\title{
LA CONEXIÓN \\ LEVANTINO-CHIPRIOTA. INDICIOS DE COMERCIO ATLÁNTICO CON EL MEDITERRÁNEO ORIENTAL DURANTE EL BRONCE FINAL (1150-950 AC)
}

\author{
THE LEVANT-CYPRIOT CONNECTION. \\ SIGNS OF ATLANTIC TRADE WITH \\ THE EASTERN MEDITERRANEAN \\ DURING THE LATE BRONZE AGE \\ (1150-950 BC)
}

\section{ALFREDO MEDEROS MARTÍN (*)}

\section{RESUMEN}

A partir de un análisis del comercio y de las secuencias cronológicas de la Península Ibérica y el área Chipro-Filistea durante parte del Bronce Final (1150-950 AC), se puede reconocer en los territorios más periféricos del Mediterráneo Oriental, la presencia de, al menos, algunas exportaciones de productos manufacturados como asadores articulados y fíbulas de codo tipo Huelva y de importaciones de vasos metálicos. Dichos productos aparecen en pequeños depósitos (Berzocana, España) o enterramientos (Amathus, Chipre) asociados a miembros de las élites dirigentes, insinuando un intercambio de regalos para establecer lazos comerciales. Se evaluan las implicaciones históricas y económicas que incentivaron dicho comercio.

(*) Becario Postdoctoral de la Dirección General de Investigación Científica y Técnica en el Department of Archaeology, University of Bristol, 11 Woodland Road, Bristol BS8 1TB, Tel. \& Fax: 1411792888 77. E-mail: archaeology@bris.ac.uk.

El artículo fue remitido en su versión final el 9-XI-96.

\begin{abstract}
Starting from an analysis of the trade and the chronological sequence between the Iberian Peninsula and the Cypro-Philistinian area during part of the Late Bronze Age (1150-950 BC), we can recognize, in the most peripheral territories of the Eastern Mediterranean, the presence at least of some exports of manufactured products in the form of articulated spits and knobbed fibulas of the Huelva type, and imports of bronze bowls. These artefacts appear in small hoards (Berzocana, Spain) or in tombs (Amathus, Cyprus), associated with members of the leading elites. This suggests an exchange of gifts in order to establish trade ties. We also evaluate the historic and economical aims of this trade.
\end{abstract}

Palabras clave: Sistemas Mundiales. Bronce Final. Periferia. Península Ibérica. Comercio. Chipre. Levante.

Key words: World Systems. Late Bronze Age. Periphery. Iberian Peninsula. Trade. Cyprus. Levant. 


\begin{tabular}{|l|l|c|c|c|c|c|c|}
\hline \multicolumn{1}{|c|}{ Artefacto } & Yacimiento & B.P. & a.C. & Máx. CAL & CAL. AC & Mín. CAL & Muestra \\
\hline Fíbula de codo & Cerro de la Miel & $3030 \pm 110$ & $\mathbf{1 0 8 0}$ & 1516 & $\mathbf{1 2 6 5}$ & 926 & UGRA-143 \\
\hline Fíbula de codo & La Requejada & $2960-95$ & $\mathbf{1 0 1 0}$ & 1415 & $\mathbf{1 1 6 0}$ & 905 & I-9604 \\
& & & & & $\mathbf{1 1 3 0}$ & & \\
\hline Fíbula de codo & La Requejada & $2820 \pm 150$ & $\mathbf{8 7 0}$ & 1401 & $\mathbf{9 8 0}$ & 765 & I-9603 \\
& & & & & $\mathbf{9 7 0}$ & & \\
\hline Fíbula de codo & Cerro de la Mora & $2920 \pm 90$ & $\mathbf{9 7 0}$ & 1393 & $\mathbf{1 1 1 6}$ & 847 & UGRA-218 \\
\hline Punta de lanza & Huelva & $2830 \pm 70$ & $\mathbf{8 8 0}$ & 1198 & $\mathbf{9 8 7}$ & 821 & CSIC-202 \\
& & & & & $\mathbf{9 5 6}$ & & $\mathbf{9 4 4}$ \\
\hline Punta de lanza & Huelva & $2820 \pm 70$ & $\mathbf{8 6 0}$ & 1160 & $\mathbf{9 7 6}$ & 821 & CSIC-203 \\
& & & & & 965 & & \\
\hline Punta de lanza & Huelva & $2820 \pm 70$ & $\mathbf{8 7 0}$ & 1160 & $\mathbf{9 7 6}$ & 817 & CSIC-206 \\
& & & & & $\mathbf{9 6 5}$ & & $\mathbf{9 3 5}$ \\
\hline Punta de lanza & Huelva & $2820 \pm 70$ & $\mathbf{8 7 0}$ & 1160 & $\mathbf{9 7 6}$ & 817 & CSIC-207 \\
\hline Punta de lanza & Huelva & & & & $\mathbf{9 6 5}$ & & $\mathbf{9 3 5}$ \\
\hline Punta de lanza & Huelva & $2800 \pm 70$ & $\mathbf{8 5 0}$ & 1126 & $\mathbf{9 2 2}$ & 809 & CSIC-204 \\
\hline
\end{tabular}

Tabla 1. Asociaciones de artefactos metálicos de la Península Ibérica en el texto con dotaciones de $\mathrm{C}^{14}$. CAL $=$ Calibración según Stuiver y Reimer (1993), versión 3.0.3.

\section{INTRODUCCIÓN}

La existencia de supuestas relaciones comerciales entre Chipre y la Península Ibérica es un tema clásico en la bibliografía, y tiene su fundamento en el estudio de Almagro Basch (1940) del depósito de la ría de Huelva, donde las fíbulas de codo, que comienzan a denominarse entonces tipo Huelva, serán integradas dentro del grupo de las fíbulas de codo chipriotas distribuidas en distintos puntos del Mediterráneo. En España, este tipo de fíbula se ha considerado siempre chipriota incluso durante los últimos años, en los que el paradigma autoctonista ha sido el predominante. Mayor prudencia ha existido respecto a la recepción de asadores articulados (Almagro Gorbea, 1974) y vasos metálicos (Schauer, 1983).

El objetivo de este trabajo es aportar una revisión del tema y plantear que en buena parte de estos artefactos, su procedencia responde tanto a una ruta Oeste-Este, como a otra
Este-Oeste que atraviesa ambos extremos del Mediterráneo. No hay por qué interpretarla necesariamente de forma unidireccional, como siempre se ha venido afirmando desde las premisas de ex oriente lux, sino inserta dentro de un tráfico en el que participarían tanto productos orientales como otros procedentes de talleres atlánticos.

La segunda meta que perseguimos es incidir sobre el argumento de la precolonización fenicia. Tradicionalmente, ésta se ha estado enfocando como un proceso de acumulación de evidencias, más o menos dudosas, a fin de rellenar el desfase arqueológico entre las primeras colonias fenicias y la supuesta fundación histórica de Cádiz. Nuestro propósito es demostrar que estos contactos se encuadran en un proceso lógico y continuado de intercambios a lo largo del Mediterráneo.

En tercer lugar, tratamos de analizar el área geográfica Sirio-Palestino-Chipriota, que ha sido defendida por Almagro Gorbea (1989: 
283) como la región de procedencia de navegaciones precoloniales unidireccionales hacia Tartessos, lo que permitiría individualizar una fase de aculturación protoorientalizante en la Península Ibérica simultáneamente a la arribada de artefactos aportados por un comercio de lujo para las élites. Nuestro propósito es aproximarnos a la dinámica interna de dicha región del Mediterráneo Oriental para tratar de integrar estos intercambios dentro de un marco histórico con motivaciones comerciales concretas e intercambios en ambas direcciones, siguiendo las premisas del análisis de los Sistemas Mundiales Antiguos (Mederos, 1995: 139-140).

\section{EL MARCO CRONOLÓGICO DE LOS INTERCAMBIOS}

Dentro de los objetivos de este análisis, las dataciones claves son las asignadas a las fíbulas tipo Huelva en la serie de fechas del depósito onubense y las fíbulas de codo procedentes de La Requejada y del Cerro de la Mora (Tabla 1).

El depósito de Huelva cuenta con una notable serie de determinaciones, con valores medios entre $c a$. 987-922 AC. Sin embargo, cabe plantearse qué datan estas fechas asignables al Bronce Final III. Si nos atenemos al depósito, contamos dentro de su homogeneidad con una mayoritaria presencia de espadas de lengua de carpa tipo Huelva más antiguas que las espadas tipo Vénat, y además con dos lanzas tipo Vénat (Ruiz-Gálvez, 1984: 282-283 y 1995: 206, 244 lám. 14/6-7) y una posible espada de espiga tipo Rixheim-Monza (Almagro Basch, 1958: lám. 11/51; Harrison, 1974-75: 230), asignable al Bronce Final I, pero que Ruiz-Gálvez (1995: 189, 236 lám. 6/6) considera una espada de lengua de carpa reutilizada. El problema de esta última atribución es que la sección del mango que presenta Ruiz-Gálvez es plana y no existe la nervadura central hasta el inicio del puño de las espadas tipo Huelva, por no hablar de los calados laterales que casi siempre caracterizan la guarda y casi tocan la nervadura central (p.e. Ruiz-Gálvez, 1995: lám. 6/1-3). No obstante, teniendo en cuenta la homogéneidad de la serie dataciones de $\mathrm{C}^{14}$, preferimos tomarlas como representativas del momento de transición entre la metalurgia tipo Huelva, Bronce Final IIIA, y la metalurgia tipo Vénat, representada por las puntas de lanza que marcarían el inicio del Bronce Final IIIB.

El depósito de Huelva suele tomarse tradicionalmente por la cantidad de artefactos metálicos documentados, como representativo del comienzo del Bronce Final III, escogiéndose las espadas y fíbulas de codo tipo Huelva como sus artefactos más emblemáticos, fechándose en la primera mitad del siglo IX a.C., en comparación con la metalurgia tipo Vénat que usualmente ha sido asignada a fines del siglo VIII y todo el siglo VII a.C., o sea 825-700 a.C.

El segundo punto de referencia es La Requejada, donde la presencia de varias leznas y de un "puñal-alabarda" tipo Vale do Carvalho "hubiera dado pie a interpretarlo como una estación del Bronce Pleno de no mediar el descubrimiento de una fíbula de codo formando parte del enterramiento" (Delibes y Fernández Manzano, 1991: 208). En la sepultura (Delibes, 1978: 229, 236-237), se optó por conceder inicialmente más valor a la datación más reciente, del 870 a.C. (ca. 980-930 AC). No obstante, recientemente se ha ido admitiendo la datación más antigua, pues ahora la sepultura es "inexcusablemente" del inicio del siglo X a.C. (Delibes y Fernández Manzano, 1991: 208), lo cual es un punto intermedio entre el 1010 a.C. y el 870 a.C.

Desde nuestro punto de vista, la desviación estándar de la determinación $870 \pm 150$ a.C. resulta más elevada que la datación más antigua, $1010 \pm 95$ a.C., que a nosotros nos parece más fiable, ca. 1160-1130 AC. Tal vez influyó que la primera procede de los huesos del esqueleto 3 y la segunda de un hogar exterior a la sepultura. Pero la presencia en dicho hogar de fragmentos de cerámica decorada de un vaso, que se encuentran también en el relleno de la sepultura donde apareció la fíbula de codo, indica la potencial validez de esta segunda determinación.

Al contar con un ejemplar de fíbula de codo tipo Huelva y una fecha del 870 a.C. que se correspondía bien con las del 880-850 a.C. de Huelva se prefirió ésta, a pesar de su mayor desviación estándar, 150 años, y de ser obtenida de una muestra de hueso, que no posee la misma

T. P., 53, n. ${ }^{\circ} 2,1996$ 


\begin{tabular}{|c|c|c|c|c|c|}
\hline \multicolumn{2}{|c|}{ CHIPRE } & \multicolumn{2}{|c|}{ CERDEÑA } & \multicolumn{2}{|c|}{ PENÍNSULA IBÉRICA } \\
\hline CF IIC & $1300-1200 / 1190$ & Nurágico II & $1300-1150$ & BF IIA/CU I & $1325 / 1300-1225$ \\
\hline CF IIIA1 & $1190-1175$ & & & BF IIB & $1225-1150$ \\
\hline CF IIIA2 & $1175-1150$ & & & & \\
\hline CF IIIB1 & $1150-1100$ & Nurágico III & $1150-850$ & BF IIC Hío-Baiões & $1150-1050$ \\
\hline CF IIIB2 & $1100-1050$ & & & & \\
\hline $\begin{array}{l}\text { CFIIIC-GC I- } \\
\text { Protogeométrico }\end{array}$ & $1050-950$ & 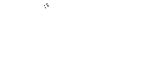 & & BF IIIA Huelva & $1050-950 / 925$ \\
\hline GC II-Geométrico & $950-850$ & & & BFIIIB Vénat & 925/950-875 \\
\hline
\end{tabular}

Tabla 2. Correlación de algunas periodizaciones propuestas para el Bronce Final del Mediterráneo. $\mathrm{CF}=\mathrm{Chipriota}$ Final. $\mathrm{BF}=$ Bronce Final. $\mathrm{CU}=$ Campos de Urnas. GC = Geométrico Chipriota. Dataciones según Merriles (1992: 51) para el Chipriota Final I-II, Cook (1988: 15-16) para el Chipriota Final III, Tykot (1994: 129) para el Nurágico y Mederos para el Bronce Final de la Península Ibérica. Excepto Merrillees y Cook, dataciones absolutas calibradas según Stuiver y Reimer (1993) versión cal. 3.0.3.

fiabilidad que las actuales a partir del AMS. De esta manera, a pesar de que una fíbula de codo tipo Huelva daba una fecha del 1010 a.C. (ca. 1150 AC), se imponía la asociación Huelva-San Román de la Hornija que aportaba una fecha $c a$. 875 a.C., esto es, $c a$. 275 años después.

La aparente asociación de la fíbula tipo Huelva con un fragmento de fíbula de codo tipo Pantálica II-Cassibile del "Bronzo Finale" italiano no hizo más que reforzar esta cronología para el depósito onubense (Almagro Basch, 1958: lám. 38/267; Almagro Gorbea, 1977: 182, 524-525, 542-543; Lo Schiavo, 1993: 301).

Si por el contrario optamos por la segunda determinación de La Requejada y utilizamos dataciones calibradas, entonces la fíbula de codo tipo Huelva de San Román de la Hornija sirve para fijar la presencia de las mismas hacia $c a$. 1150 AC. Consecuentemente, si se quiere seguir manteniendo la asociación espadas y fíbulas tipo Huelva como indicativa de los inicios del Bronce Final III, ello implicaría que dicho periodo ya habría comenzado hacia ca. $1150 \mathrm{AC}$.

Téngase en cuenta que si optásemos por escoger las fechas de Huelva como el inicio del Bronce Final III, ca. 950 AC, sólo nos quedarían unos 100 años de desarrollo de la metalurgia tipo Huelva y tipo Vénat, previo a la llegada de los fenicios a Morro de Mezquitilla, que en la fase A-B1 dan fechas ca. 897-870 AC.

Las dataciones de los yacimientos granadinos del Cerro de la Miel y del Cerro de la Mora (Carrasco et alii, 1985: 294, 305) apoyan también esta mayor antigüedad de las cronologías. La del Cerro de la Miel, 1516 (1265) 926 AC, parece resultar demasiado alta ya que tradicionalmente se le ha asignado una cronología del Bronce Final III, mientras la fecha indica un momento del Bronce Final II. Sin embargo, al proceder de un poste de cabaña, es posible que la madera esté datando un momento previo. Por su parte, la procedente del Cerro de la Mora, 1393 (1116) 847 AC, se mueve en la banda de La Requejada.

Consecuentemente, la serie de Huelva debe datar más o menos el momento final del Bronce Final IIIA, y su transición con la metalurgia tipo Vénat del Bronce Final IIIB, $c a .950$ AC, mientras que la fíbula de San Román marcaría el inicio del Bronce Final IIC, tipo Hío-Baiões, ca. 1150 AC, estrechamente relacionada con el Bronce Final IIIA tipo Huelva (Tabla 2).

\section{INDICIOS DE TRÁFICO CON EL MEDITERRÁNEO ORIENTAL}

Dentro del registro arqueológico de la Península Ibérica contamos con algunos artefactos, como las fíbulas de codo tipo Huelva, los asadores articulados y un vaso metálico que pudieron haber sido objeto de intercambio comercial durante el Bronce Final Atlántico con uno o varios puntos del Mediterráneo Oriental.

\section{Fíbulas de codo tipo Huelva}

Fuera de la Península Ibérica contamos con un ejemplar particularmente claro de Kourion

T. P., 53, n. ${ }^{\circ} 2,1996$ 


\begin{tabular}{|l|l|c|c|c|l|}
\hline \multicolumn{1}{|c|}{ Yacimiento } & Región & País & Tipo & N. $^{\circ}$ & \multicolumn{1}{|c|}{ Bibliografía } \\
\hline Ría de Huelva & Andalucía & España & Depósito & 9 & $\begin{array}{l}\text { Almagro Basch, 1940: 138, fig. 58, lám. V; } \\
\text { 1957-58: 198, fig. 1/1-2; 1958: lám. 38/257- } \\
\text { 265 y 1966: 186, fig. 73/1-3. }\end{array}$ \\
\hline Cerro de la Miel & Andalucía & España & $\begin{array}{c}\text { Poblado } \\
\text { nivel A6 }\end{array}$ & $\begin{array}{c}1+ \\
i 1\end{array}$ & Carrasco et alii, 1985: 297, fig. 22/102-103. \\
\hline Cerro de la Mora & Andalucía & España & Poblado & 6 & Inéditas; Carrasco et alii, 1985: 296. \\
\hline Cerro de los Infantes & Andalucía & España & $\begin{array}{c}\text { Poblado } \\
\text { fase IV }\end{array}$ & 1 & Mendoza et alii, 1981: 191, abb. 12f. \\
\hline ¿Cerro de la Encina? & Andalucía & España & & 1 & Schüle, 1969: 143-144, abb. 39b. \\
\hline Cerro del Berrueco & Castilla y León & España & & 1 & $\begin{array}{l}\text { Morán, 1923-34: lám. 8; Maluquer, 1958: 86, } \\
\text { fig. 26. }\end{array}$ \\
\hline La Requejada & Castilla y León & España & Sep. 3 & 1 & Delibes, 1978: 236, fig. 7/36. \\
\hline Alto de la Yecla & Castilla y León & España & & 1 & González Salas, 1945: 32, lám. 19. \\
\hline Burgos- ¿Palencia? & Castilla y León & Chipre & & 1 & Almagro Basch, 1940: 139, fig. 60/2. \\
\hline Kourion & Limasol & Chipre & & 1 & Cesnola, 1903: pl. 63/9. \\
\hline Amathus & Limasol & Chipre & Sep. 3 & 1 & Karageorghis, 1987: 719, 723, fig. 193. \\
\hline ¿Kition? & Larnaca & Chipre & & 1 & Buchholz, 1986: 225 abb. 2b, 229. \\
\hline Megiddo & Norte & Palestina & $\begin{array}{l}\text { Poblado, } \\
\text { nivel Va }\end{array}$ & 1 & Loud, 1986: 223/78. \\
\hline Samaria-Sebaste & Judea y Samaria & Palestina & $\begin{array}{l}\text { Poblado, } \\
\text { nivel III }\end{array}$ & 1 & Crowfoot et alii, 1957: fig. 102/1. \\
\hline
\end{tabular}

Tabla 3. Distribución de las fíbulas de codo tipo Huelva en el Mediterráneo.

en Chipre (Cesnola, 1903). Fue publicado inicialmente como chipriota, criterio mantenido por Myres (1914: 143, $\mathrm{n}^{\circ}$ 4741) y Blinkenberg (1926: 247-248) quien lo incluye en su tipo chipriota XIII 14a. Posiblemente de Kition procede otro (Buchholz, 1986). Finalmente, un tercer ejemplar fue recientemente localizado en la sepultura $\mathrm{n}^{\circ} 523$ de Amathus (Karageorghis, 1987), asignable al Protogeométrico o Geométrico Chipriota I, $c a$. 1050-950 AC, y significativamente está acompañado por un asador articulado.

En España, este tipo tras ser consignado inicialmente como siciliano del tipo Cassibile (Almagro Basch, 1940: 138, 141; Hawkes, 1952: 103), derivado suyo (Birmingham, 1963: 100103) o fruto de una convergencia chipriota y siciliana (Delibes, 1978: 245), pasó a ser valorado mayoritariamente como chipriota por los investigadores españoles (Almagro Basch, 1957-58: 199 y 1966: 184; Almagro Gorbea, 1977: 182, 524-525, 542-543 y 1989: 283; Molina González,
1978: 215; Blázquez, 1985-86: 486; Ruiz-Gálvez, 1986: 29 y 1993: 60; Alvar, 1988: 434), y extranjeros (Hencken, 1956: 215; Coles, 1962: 159; Schüle, 1969: 25-26, 143; Coffyn, 1985: 152-156; Burgess, 1991: 37; Coffyn y Sion, 1993: 310, carte 5).

En la última revisión de las fíbulas chipriotas, Buchholz (1986: 229-231, fig. 9) considera a la fíbulas tipo Huelva dentro de su grupo más antiguo, del que derivarían todos los demás ejemplares chipriotas, fechándolo ca. 1200-700 AC, modelo teórico a nivel tipológico y cronológico aún por contrastar adecuadamente. Por el contrario, Lo Schiavo (1991: 220) opta por mantener un criterio algo más escéptico considerando al tipo Huelva como "aparentemente" chipriota, ya que podría tratarse de un tipo local imitando el gusto chipriota y siciliano (Lo Schiavo, 1993: 501).

Uno de los principales problemas que ha existido al caracterizar estas fíbulas ha sido las genéricas atribuciones como tipo Huelva dadas 


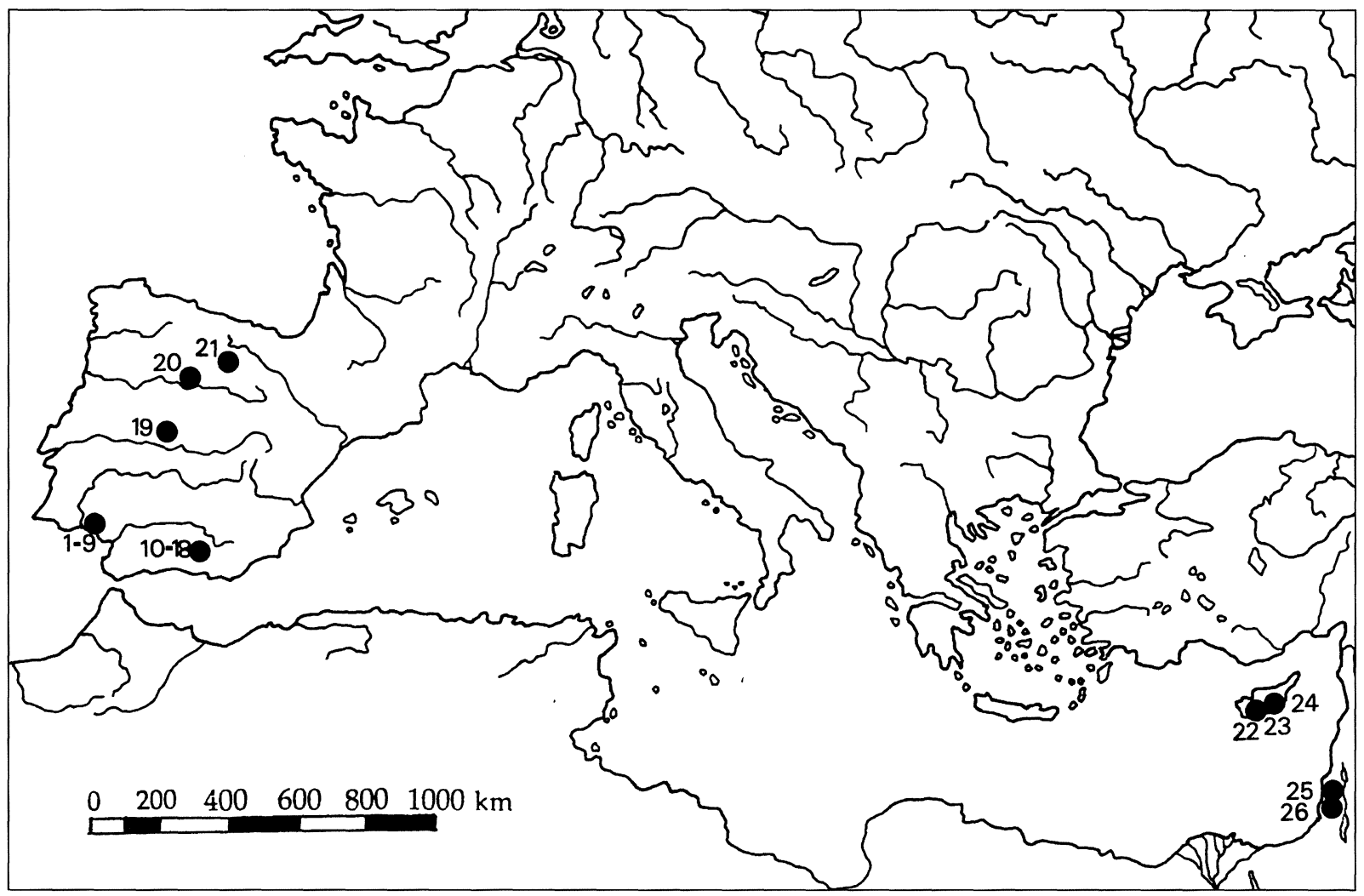

Fig. 1. Distribución de las fíbulas de codo tipo Huelva en el Mediterráneo. 1-9: Ría de Huelva. 10: Cerro de la Miel (Moraleda de Zafayona, Granada). 11-16: Cerro de la Mora (Moraleda de Zafayona, Granada). 17: Cerro de los Infantes (Pinos Puente, Granada). 18: ¿Cerro de la Encina? (Monachil, Granada). 19: El Berrueco (Salamanca). 20: La Requejada (San Román de la Hornija, Valladolid). 21: Alto de la Yecla (Santo Domingo de Silos, Burgos). 22: Kourion. 23: Amathus. 24: Larnaca. 25: Megiddo. 26: Samaría. No figuran una fíbula de Burgos-Palencia (Almagro Basch, 1940: fig. 60/2), por desconocerse con seguridad la provincia de procedencia, y una fíbula chipriota (Almagro Basch, 1966: fig. 70/6), sin procedencia concreta en Chipre, de la antigua colección del Seminario de Historia Primitiva, Universidad Complutense de Madrid.

por Almagro Basch en mapas, sin una adecuada caracterización interna de su morfología e indicación concreta de donde ha obtenido la referencia para otorgarle dicha asignación.

$\mathrm{Si}$ observamos las listas aportadas por Almagro Basch (1957-58: 200, fig. 3 y 1966: 185, fig. 72), se aprecia que, junto al tipo XIII-14 de Blinkenberg que incluía sólo la fíbula chipriota de Kourion, Almagro Basch añade el tipo XIII15 que corresponde a modelos más evolucionados. Este segundo subtipo de Blinkenberg (1926: 248-253), o forma desarrollada de Birmingham (1963:101), incluye ejemplares de Amathus, Kition, Kourion, Tamassos, Lindos (Rodas), Kameiros (Rodas) y Egina, que son a veces citados por Almagro Basch (1957-58: fig. 3/3-5 y 1966: fig. $72 / 3,5$ y 8 ). La fíbula de la misteriosa Caria que localiza en Asia Menor (Almagro Basch, 1957-58: fig. 3/3 y 1966: fig. 72/4) es simplemente un error geográfico y ortográfico de la necrópolis de Kameiros, situada en el N.O. de Rodas, el cual no parece advertir Coffyn (1985: 155; Coffyn y Sion, 1993: 310) aceptándola como su fíbula chipriota $\mathrm{n}^{\circ} 40$.

Otras fíbulas de Palestina que aparecen nuevas en su segundo mapa (Almagro Basch, 1966: fig 72) como Samaria, Gezer y Tell elMutesellim son del tipo desarrollado que toma de Birmingham (1963: 101), con la matización además de que Tell el-Mutesellim está repetida, pues es la actual denominación Megiddo. Recientemente, por segunda vez, los tipos XIII-14 y XIII-15 de Blinkenberg y los ejemplos palestinos ya citados son agrupadas por 
Coffyn (1985: 155, carte 24; Coffyn y Sion, 1993: 310, carte 5) como si se tratara del mismo tipo de fíbula, planteamiento que no compartimos y da una visión distorsionada de su distribución real.

Finalmente, dos fíbulas españolas de Guadalajara-Soria y Roquizal de Rullo (Zaragoza) que también Almagro Basch (1957-58: fig. 3/10 y 11) considera de codo no son tales (Almagro Basch, 1940: fig. 60/1 y 61).

Desde nuestro punto de vista, la fíbula de codo tipo Huelva es un tipo fabricado en la Península Ibérica, que tiene una distribución concentrada en dos regiones, la Meseta Norte a ambas márgenes del Valle Alto y Medio del Duero y Andalucía Oriental (Tabla 3; Fig. 1).

Esta fíbula se encuentra datada en La Requejada, $c a .1150 \mathrm{AC}$, en un contexto cerrado, y mientras no se documenten evidencias precisas en contextos claros de Chipre o Italia, no existen argumentos para presuponer una procedencia oriental, y sí al contrario, presumir un posible origen occidental para las tres fíbulas chipriotas.

En todo caso debe quedar claro que entre las fíbulas tipo Huelva de la Península Ibérica existen matices diferenciales. Así, el ejemplar del Cerro de la Miel está elaborado con dos piezas remachadas (Carrasco et alii, 1985: 298) y por su decoración se aproxima particularmente a la fíbula de La Requejada, en contraposición con las procedentes de Huelva que parecen elaboradas en una sola pieza. La coincidencia formal entre los ejemplares más antiguos y macizos está reafirmada por la mayor antigüedad de las dataciones de sus contextos.

Otro ejemplar de estas características procede del estrato VA de Megiddo (Loud, 1948), fechado en su momento hacia 1060-1000 a.C. (Lamon y Shipton, 1939: xxvii), pero que Albright (1940: 548) amplió a 1050-950 a.C., Gjerstad (1948: 421) modernizó aún más, entre el 1000-900 a.C., Wightman (1985: 126-128) rebaja a $c a .965-900 / 890$ a.C. y Kempinski (1989: 10) actualmente sitúa entre el $980-920$ a.C., en la fase del Hierro IIA. Finalmente, la fíbula de Samaria-Sebaste nivel III (Crowfoot et alii, 1957), es correlacionable con Megido III, $c a$. 810-790 AC.
La presencia del ejemplar de Megiddo fue resaltada en su momento por Hencken (1956: 213-215), considerando que de él derivarían las fíbulas de codo sicilianas tipo Pantálica II y las de codo tipo Huelva de Chipre y la Península Ibérica. Esta hipótesis pierde su validez cuando trabajamos con cronologías calibradas, pues frente al ca. 950 AC del estrato VA de Megiddo, se dan fechas del 1200-700 AC para Chipre, 1200-900 AC para Pantalica II y ca. 1150 AC y 1116 AC para la Península Ibérica. Además, desde la muerte de Salomón, ca. 931-922 AC, contamos con unas listas detalladas de cada monarca en Israel y Judea por lo que resulta difícil que en un futuro la cronología de Megiddo VA pueda retrotraerse demasiado.

\section{Asadores articulados}

Un asador articulado procedente de la sepultura en cámara $\mathrm{n}^{\circ} 523$ de Amathus en Chipre (Karageorghis y Lo Schiavo, 1989: 16) se fecha hacia $c a .1000 \mathrm{AC}$. El resto del ajuar de la sepultura se extiende (Karageorghis, 1987: 719, nota 98) entre el Protogeométrico o Geométrico Chipriota I, 1050-950 AC, y el Chipriota Arcaico I, 750-600 AC, ya que hay una reutilización, y aunque Karageorghis encuadra el asador en el Geométrico Chipriota I, duda si pertenecerá a la inhumación más reciente. Por otra parte, hay que tener presente que no necesariamente la pieza se hubo de depositar a su arribada a Chipre, con lo que la cronología del momento de su fabricación aún podría ser más antigua que la primera fase de utilización de la tumba.

Un dato llamativo del carácter exógeno de una pieza de estas características en Chipre es que Karageorghis (1987: 719), en su publicación preliminar, reconoce que no ha podido identificar el tipo de artefacto al que correspondería pese a conservarse casi completo.

A. Coffyn y H. Sion (1993: 287) advierten que la barra doblada en forma de U, habitualmente móvil, aquí parece maciza, lo que le da un matiz diferencial a la pieza, aunque señalan los problemas de corrosión que presenta. Su mal estado de conservación en ese sector dificulta su valoración y resulta desalentador el di- 


\begin{tabular}{|c|c|c|c|c|c|c|c|}
\hline Yacimiento & $\begin{array}{l}\text { Municipio } \\
\text { y distrito }\end{array}$ & Provincia & Región & País & Tipo & $\mathrm{N} .^{\circ}$ & Bibliografía \\
\hline Isleham & Camdridge shire & & East Anglia & Reino Unido & Depósito & 1 & $\begin{array}{l}\text { O'Connor, 1980: } \\
\text { fig. } 45 / 37\end{array}$ \\
\hline Saltwood & Kent & & South-East & Reino Unido & & 1 & $\begin{array}{l}\text { Coffyn, 1985: } \\
\text { carte } 21\end{array}$ \\
\hline Foret de Compiègne & & Oise & Picardie & Francia & & 1 & $\begin{array}{l}\text { Mohen, 1977: } 34 \text {, } \\
\text { fig. } 1 / 3\end{array}$ \\
\hline Sainte-Marguerite & Pornichet & Loire-Atlantique & Pays de la Loire & Francia & Depósito & 1 & $\begin{array}{l}\text { Bigoteau, 1974-75, } \\
\text { pl. 12/81 }\end{array}$ \\
\hline Challans & & Vendée & Pays de la Loire & Francia & Depósito & 1 & $\begin{array}{l}\text { Mohen, 1977: } 34 \text {, } \\
\text { fig. } 1 / 4\end{array}$ \\
\hline Notre-Dame d'Or & Mirabeau & Vienne & Poitiu-Charentes & Francia & Depósito & 1 & $\begin{array}{l}\text { Mohen, 1977: } 34 \text {, } \\
\text { fig. 1/1 }\end{array}$ \\
\hline Venat & Saint-Yriex & Charente & Poitiu-Charentes & Francia & Depósito & 1 & $\begin{array}{l}\text { Mohen, 1977: } 34 \text {, } \\
\text { fig. } 1 / 2\end{array}$ \\
\hline Río Dordogne & Port-Sainte-Foy & Dordogne & Aquitania & Francia & Dragado & 1 & $\begin{array}{l}\text { Chevillot, 1989: } \\
\text { 161-162, fig. 32 } \\
\text { y 1991: 156-157, } \\
\text { pl. } 8 / 14\end{array}$ \\
\hline Monte da Costa-Figueira & $\begin{array}{l}\text { Paredes do Douro, } \\
\text { Porto }\end{array}$ & Braga, Minho & Norte & Portugal & ¿aislado? & 1 & $\begin{array}{l}\text { Cardozo, 1946: 3-4, } \\
6 \text { fig. 5; Kalb, 1980: } \\
\text { 28, 40, abb. } 4 / 23\end{array}$ \\
\hline Nossa Senhora da Guia, Baiões & $\begin{array}{l}\text { Sao Pedro do Sul, } \\
\text { Viseu } \\
\end{array}$ & Beira Alta & Centro & Portugal & Depósito & $\begin{array}{l}1+ \\
i 1 ?\end{array}$ & $\begin{array}{l}\text { Kalb, } 1980: 30,45 \\
\text { Abb. } 9 / 43 / 21,27\end{array}$ \\
\hline Serra da Alvaiázere & Alvaiázere, Leiria & Beira Litoral & Centro & Portugal & Depósito & 1 & $\begin{array}{l}\text { Almagro Gorbea, } \\
\text { 1974: } 355-357 \text {, fig. } 1 \text {; } \\
\text { Kalb, 1980: 30, 46, } \\
\text { abb. 10/2-4, 7-8 }\end{array}$ \\
\hline Cachouça & $\begin{array}{l}\text { Idanha-a-Nova, } \\
\text { Castelo Branco } \\
\end{array}$ & Beira Baixa & Centro & Portugal & Poblado & 1 & Vilaça, 1990: 168 \\
\hline Cerca del Cerro del Berrueco & & Salamanca & Castilla y León & España & ¿Aislado? & 1 & $\begin{array}{l}\text { Morán, 1921; } \\
\text { Almagro Gorbea, } \\
\text { 1974: 376, 362 fig. 4/3 }\end{array}$ \\
\hline Orellana la Vieja & & Badajoz & Extremadura & España & & 1 & $\begin{array}{l}\text { Almagro Gorbea, } \\
\text { 1986: } 355 \text {, fig. } 3\end{array}$ \\
\hline Monte Sa Idda & Decimoputzu & Cagliari & Cerdeña & Italia & Depósito & 1 & $\begin{array}{l}\text { Taramelli, 1921: } \\
56-57 \text {, fig. } 79\end{array}$ \\
\hline Grotte Pirosu-Su Benatzu & Santadi & Cagliari & Cerdeña & Italia & Santuario & 1 & Lo Shiavo, 1991: 216 \\
\hline Amathonte-Amathus & & & Limasol & Chipre & Sepultura & 1 & $\begin{array}{l}\text { Karageorghis, 1987: } \\
719,721 \text {, fig. } 187\end{array}$ \\
\hline
\end{tabular}

Tabla 4. Distribución de los asadores articulados en la Europa Atlántica y el Mediterráneo Central y Oriental.

bujo, tanto del engarce del pivote móvil dentro de la barra del asador como de la unión de la barra doblada en forma de U, aunque se nos ofrece una reconstrucción del modelo. En todo caso, el pomo semicircular acabado en una anilla cilíndrica, la punta, el pivote móvil y el arranque de un motivo decorativo en el lado opuesto de la barra doblada en forma de U responden al tipo habitual.

Algunos autores como Burgess (1991: 40) consideran que los asadores articulados y los calderos con remaches proceden de Gran

T. P., 53, n. ${ }^{\circ} 2,1996$ 


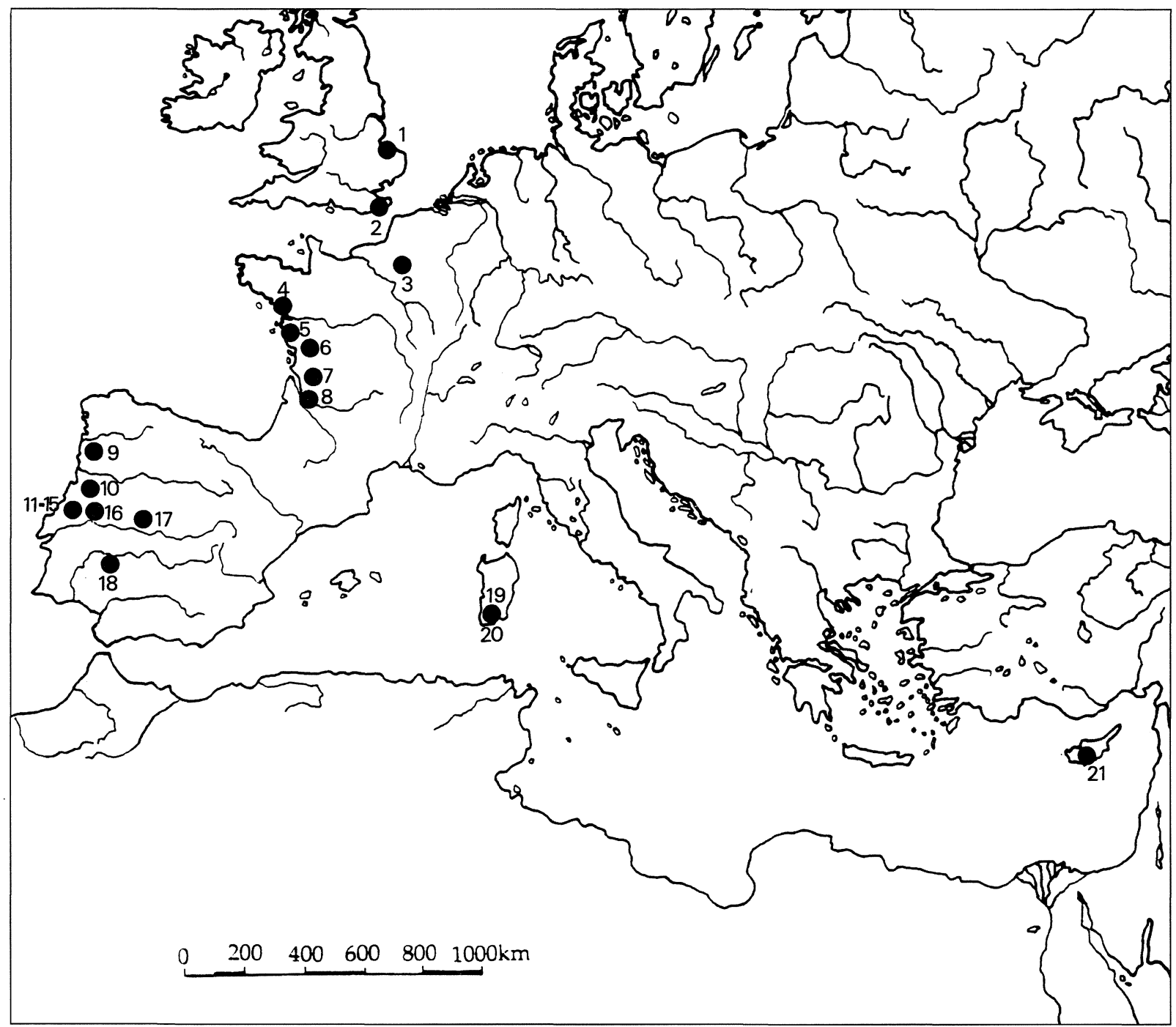

Fig. 2. Distribución de los asadores articulados en la Europa Atlántica y el Mediterráneo Central y Oriental. 1: Isleham. 2: Saltwood. 3: Foret de Compiègne. 4: Sainte-Marguerite. 5: Challans. 6: N. D. d’Or. 7: Venat. 8: Río Dordogne. 9: Monte da Costa. 10: N. S. da Guia, Baiões. 11-15: Serra da Alvaiázere. 16: Cachouça. 17: Inmediaciones Cerro del Berrueco. 18: Orellana la vieja. 19: Monte Sa Idda. 20: Grotte Pirosu. 21: Amathus.

Bretaña, y su uso se difundiría a la Península Ibérica hacia el año 1000 AC. Esta hipótesis choca con impedimentos como la total ausencia de los asadores articulados en Irlanda en la fase Dowris, equivalente a nuestro Bronce Final III. Por el contrario, los autores franceses (Coffyn, 1985: 55) tienden a caracterizarlos como originarios del centro-oeste francés, apoyándose en su distribución. Respecto a los investigadores españoles, en la inicial sistematización de los asadores de la Península
Ibérica, Almagro Gorbea (1974: 380, 384) apunta un origen centroeuropeo para este tipo, en torno al siglo VIII a.C., basándose en la decoración de pájaros de un ejemplar de Serra de Alvaiázere (Almagro Gorbea, 1974: fig. $1 / 1$ y $9 / 1$ ).

Sin embargo, actualmente la Península Ibérica es la zona con mayor número de presencias (Tabla 4; Fig. 2), y sólo los cinco de Serra de Alvaiázere son tantos como los de toda Francia. Quizás habría que presuponer 


\begin{tabular}{|c|c|c|c|c|c|c|c|c|}
\hline Recipiente & Yacimiento & $\begin{array}{l}\text { Municipio } \\
\text { y distrito }\end{array}$ & Provincia & Región & País & Tipo & $\mathrm{N} .^{\circ}$ & Bibliografía \\
\hline $\begin{array}{l}\text { Cuencos, uno } \\
\text { con ónfalo }\end{array}$ & $\begin{array}{l}\text { Nossa Senhora } \\
\text { da Guia, } \\
\text { Baiões }\end{array}$ & $\begin{array}{l}\text { Sao Pedro do Sul, } \\
\text { Viseu }\end{array}$ & Beira Alta & Centro & Portugal & Depósito & 6 & $\begin{array}{l}\text { Kalb, 1980: } 30,45 \text {, } \\
\text { abb. } 9 / 43 / 24 \text {; da Silva } \\
\text { et al., 1984: } 81-82 \text {, } \\
101 \text { est. VI/2-5 }\end{array}$ \\
\hline $\begin{array}{l}\text { Cuenco con } \\
\text { ónfalo y } \\
\text { decoración } \\
\text { incisa }\end{array}$ & $\begin{array}{l}\text { Nossa Senhora } \\
\text { da Guía, } \\
\text { Baiôes }\end{array}$ & $\begin{array}{l}\text { Sao Pedro do Sul, } \\
\text { Viseu }\end{array}$ & Beira Alta & Centro & Portugal & Depósito & 1 & $\begin{array}{l}\text { Da Silva et alii, 1984: } \\
81,101 \text { est. VI/1 }\end{array}$ \\
\hline $\begin{array}{l}\text { Cuenco con } \\
\text { pie y ónfalo }\end{array}$ & El Terero & Berzocana & Cáceres & Extremadura & España & Depósito & 1 & $\begin{array}{l}\text { Callejo y Blanco, } \\
\text { 1960: } 250\end{array}$ \\
\hline $\begin{array}{l}\text { Caldero con } \\
\text { asa móvil }\end{array}$ & Cala Gonone & Dorgali & Nuoro & Cerdeña & Italia & & 1 & Guido, 1963: pl. 58 \\
\hline $\begin{array}{l}\text { Caldero con } \\
\text { asa móvil }\end{array}$ & Grotta Su Bentichedu & Oliena & Nuoro & Cerdeña & Italia & & 1 & $\begin{array}{l}\text { Lo Schiavo, 1978: } \\
89-91 \text {, pl. 28/2 }\end{array}$ \\
\hline $\begin{array}{l}\text { Cuenco con } \\
\text { asa móvil }\end{array}$ & Monte San Vicenzo & Caldare & Agriento & Sicilia & Italia & Sepultura & 1 & $\begin{array}{l}\text { Orsi, 1897: 12-13, } \\
\text { lám. } 2 / 9 .\end{array}$ \\
\hline $\begin{array}{l}\text { Fuente } \\
\text { con asas }\end{array}$ & Monte San Vicenzo & Caldare & Agriento & Sicilia & Italia & $\begin{array}{c}\text { Misma } \\
\text { sepultura }\end{array}$ & 1 & $\begin{array}{l}\text { Orsi, 1897: 12-13, } \\
\text { lám. 2/8. }\end{array}$ \\
\hline $\begin{array}{l}\text { Fuente } \\
\text { con asas }\end{array}$ & Monte Campanella & Milena & Agriento & Sicilia & Italia & ¿sepultura? & 1 & $\begin{array}{l}\text { La Rosa, 1979: } \\
\text { fig. 6d, tav. 14/1-3 }\end{array}$ \\
\hline Cuenco & Thapsos & & Catania & Sicilia & Italia & Sep. 57 & 1 & Orsi, 1895: 131, fig. 45. \\
\hline
\end{tabular}

Tabla 5. Pequeños recipientes metálicos con formas reconstruibles del Mediterráneo Central y Occidental durante el Bronce Final. No se señalan fragmentos aislados de asas o fragmentos informes. Se exceptúan los calderos con remaches típicos del Bronce Final Atlántico.

su producción en regiones diferentes, aunque dado su excepcionalidad, sólo veinte ejemplares conocidos, diez de ellos en la Península Ibérica, es obvio que hubo de existir una producción limitada a uno o pocos centros. Las similitudes que Lo Schiavo (1991: 216) encuentra entre los ejemplares de Grotte Pirosu y El Berrueco favorecen propugnar una procedencia ibérica para los ejemplares de Cerdeña. Quizás otro tanto suceda con el de Amathus.

La cronología de los asadores articulados resulta problemática por la falta de contextos adecuados. Los del Berrueco y Monte da Costa carecen de datos al respecto. Los de Serra da Alvaiázere van acompañados por hachas unifaciales con una anilla, las cuales también aparecen en el depósito de N.S. da Guia de Baiões, junto a hoces de enmangue tubular, e indican para ambos casos una posible cronología dentro del Bronce Final IIC entre el 1150-1050 AC.

T. P., 53, n. ${ }^{\circ} 2,1996$

\section{Vasos metálicos}

Una presumible procedencia oriental cabe asignar al cuenco metálico del depósito de Berzocana (Cáceres) dado lo excepcional de su presencia en la Península Ibérica. Tras su descubrimiento (Callejo y Blanco Freijeiro, 1960: 250 ), ha sido valorado por distintos autores, asignándole una cronología reciente (Blázquez, 1968: 105; Hawkes, 1971: 40) dentro del ambiente orientalizante, siglos VII o VIII a.C. para Harrison (1988: 85).

Otros investigadores, por el contrario, encontraron paralelos centroeuropeos, hacia mediados del siglo VIII a.C. (Almagro Basch, 1967 y 1969: 276), hipótesis que no ha gozado de aceptación. En un punto intermedio, Almagro Gorbea $(1977: 29,244)$ orientó la búsqueda de referentes hacia Egipto encontrando los mejores paralelos en el depósito de Tell Basta que fechó hacia el siglo VIII a.C. o inicios del siglo VII a.C., si bien más recientemente (Al- 


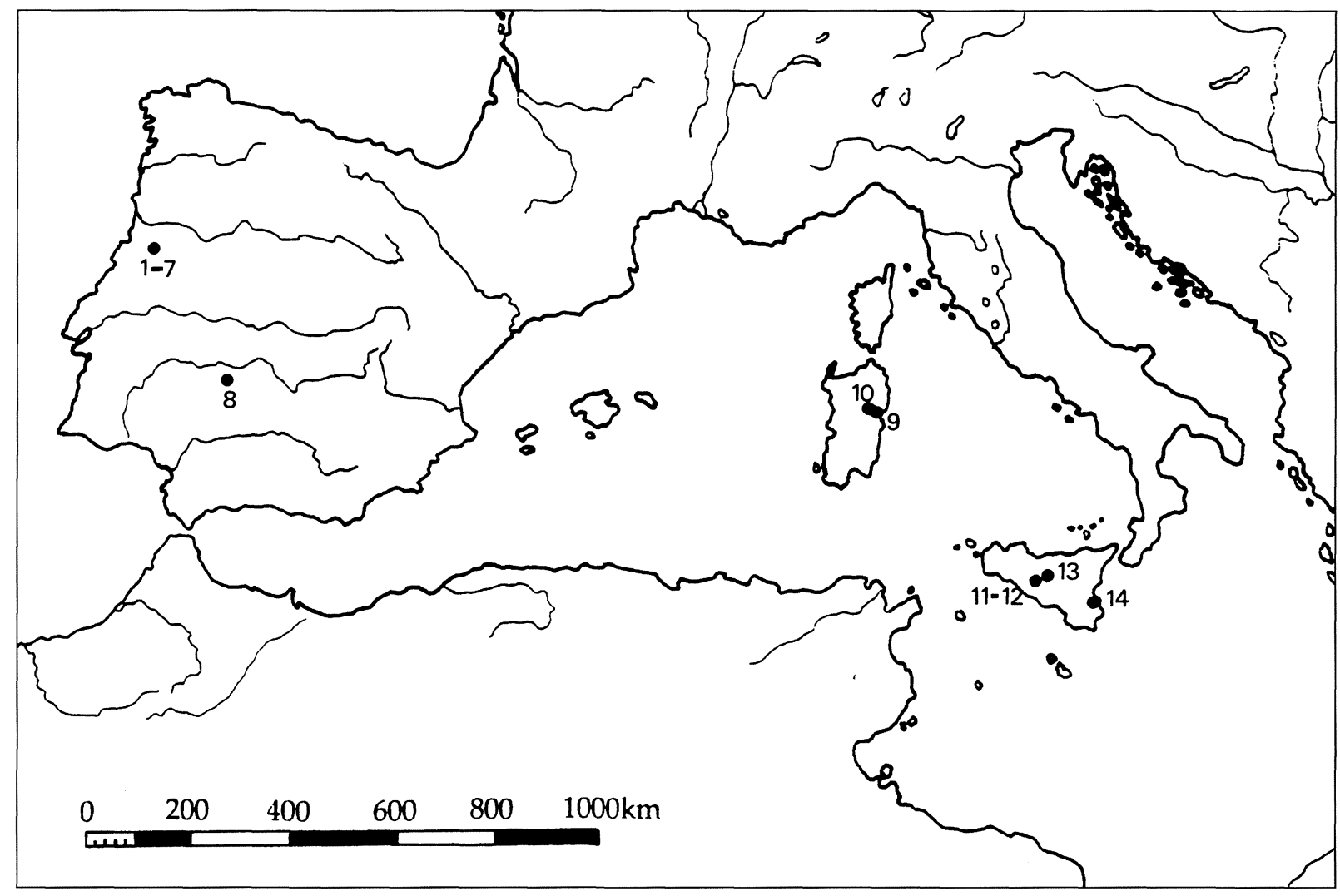

Fig. 3. Distribución de pequeños recipientes metálicos en el Mediterráneo Central y Occidental. 1-7: N.S. da Guia, Baiões. 8: Berzocana. 9: Cala Gonone. 10: Grotta Su Bentichedu. 11-12: Monte San Vicenzo. 13: Monte Campanella. 14: Thapsos.

magro Gorbea, 1989: 283) se inclina hacia el año 1000 a.C.

Esta orientación hacia referentes egipciopalestinos y una cronología antigua del siglo XII a.C. es desarrollada por Schauer (1983: $179,182)$, quien plantea la presencia de este tipo de recipientes tanto en Palestina entre los siglos XV-XI a.C, coetáneos al Imperio Nuevo, dinastías XVIII-XX (1550-1070 a.C.), como en Chipre, Hala Sultan Tekké (Chipriota Final IIIA1), Amathus sep. 22 o Gastria-Alaas sep. 6/8 (Protogeométrico) y Lapithos sep. 409 (Geométrico I). Amathus y Lapithos también son los ejemplos tomados por Niemeyer (1984: 8-9) para apoyar la procedencia chipriota del recipiente de Berzocana, asignándolos a los siglos XIV-XII a.C., al igual que Alvar (1988: 434) y Burgess (1991: 26).

Un elemento fundamental para la cronología del recipiente es su asociación con dos tor- ques de oro macizos con decoración incisa (Perea, 1991: 100), fechados por Almagro Gorbea (1977: 244) entre los siglos XII-X a.C. P. Schauer (1983: 179) los conecta con los depósitos franceses de Hinguet (Berry) (Briard, 1965: 144, pl. 45-47) y Malassis (Berry) (Briard et alii, 1969: 37) a los que otorga una cronología de los siglos XIII-XII a.C. y Burgess (1991: 27) retrae estas fechas a los siglos XIV-XIII a.C. resaltando que la decoración incisa repite los motivos característicos de los brazaletes del Bronce Medio II Bretón tipo Bignan (Briard, 1965), los cuales se concentran en Francia (Briard et alii, 1969: 65) y el extremo sureste de Inglaterra (Rowlands, 1971: 195, fig. 4).

Por nuestra parte queremos propugnar una tesis diferente a partir de su distribución (Tabla 5; Fig. 3). Los recipientes metálicos presentes en la Península Ibérica, concretamente los del depósito de Baiões que son los únicos ejempla- 
res conocidos, si nos atenemos a su decoración parecen responder a modelos propios del Bronce Final atlántico.

Los ejemplares de Cerdeña, al igual que algún fragmento de asa no tratado aquí, se concentran en la mitad oriental de la isla alrededor de Nuoro, tal como sucede con las espadas pistiliformes del Bronce Final II, en conexión con las corrientes marinas que facilitan el acceso a la isla desde Italia. Según Lo Schiavo et alii (1985: 32-33) cabe atribuirles una manufactura local y cronologías recientes, muy del final de la Edad del Bronce, lo que equivaldría a un momento ya avanzado del Nurágico III.

Los recipientes de Sicilia se distribuyen también en la prolongación de la corriente marina que desciende desde la mitad oriental de Cerdeña hacia el Sur de Sicilia, a lo largo de la costa sur y sureste. L. Vagnetti (1968), para el de Monte San Vincenzo, y Lo Schiavo et alii $(1985: 32,62)$ se inclinan por referentes chipriotas del siglo XIII AC, o lo que es lo mismo, del Chipriota Final IIC. Además, el patrón de deposición resulta aquí diferente a los ejemplos de la Península Ibérica, ya que tienden a localizarse dentro de ajuares en sepulturas y no en depósitos metálicos (Tabla 5). No obstante, sería deseable que se publicasen dibujos adecuados con secciones para pronunciarse con ciertas garantías sobre estos paralelos.

Respecto al cuenco de Berzocana, habría que valorar los torques de oro macizos con decoración incisa, los cuales se reparten en diez casos en la Península Ibérica (Coffyn, 1985: 129, carte 15), frente a tres en el noroeste de Francia, dos en Bretaña, uno en el Pays de la Loire y dos en la región del sureste de Inglaterra. En la Bretaña francesa, serían asignables a un Bronce Final I, que podríamos correlacionar con un Bronce Final IC, circa 1425-1325/1300 AC de la Península Ibérica. Sin embargo, hay que tener en cuenta que, dado el valor intrínseco de los mismos, puede esperarse un prolongado uso previo de dichos torques hasta su deposición.

Un dato favorable para fechar el cuenco metálico de Berzocana en el Bronce Final IIIA, $c a$. 1050-950 AC, es que existe un ejemplar práctica-

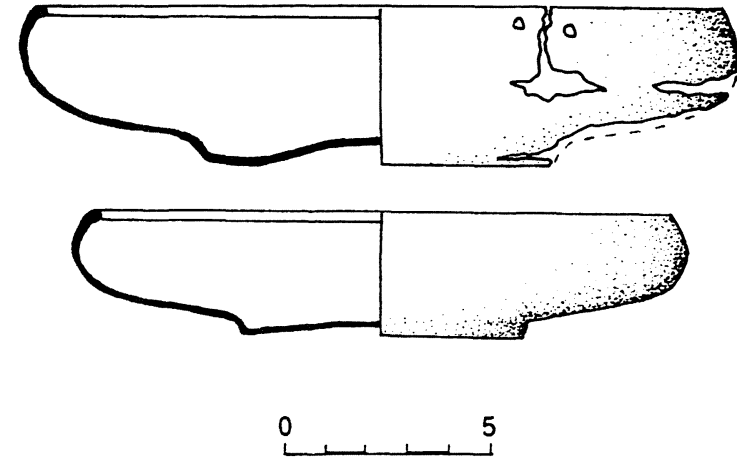

Fig. 4. Recipientes metálicos de Berzocana (España) y Chipre. Nuevos dibujos a partir de Almagro gorbea (1977: 23, fig. 6/3) y Matthaus (1985: taf. 19/336).

mente similar (Fig. 4) procedente genéricamente de Chipre (Myres, 1914: 496; Matthäus, 1985: 115, taf. 19/336). Sus dimensiones, $15.1 \mathrm{cms}$. de diámetro máximo y $3.4 \mathrm{cms}$. de altura, se corresponden bien con el de Berzocana, $17 \mathrm{cms}$. de diámetro máximo y $4 \mathrm{cms}$. de altura. La sugerencia de Almagro Gorbea (1977: 24, 244) de que los dos agujeros se corresponderían con un asa perdida, creemos que podría interpretarse de forma diferente: como un lañado para reparar una fractura. Si se depositó con sólo dos torques de oro es presumible que su posesión fuera considerada valiosa. En favor de esta idea puede argüirse que ambas perforaciones no se disponen simétricamente y que una de las fracturas actuales está entre ambas perforaciones. El ejemplar chipriota posee además el borde convergente marcado - del que carece el de Lapithos sep. 409, referente esgrimido por Schauer (1983) y Niemeyer (1984) - , con paredes y bordes ligeramente divergentes también el pie marcado con ónfalo.

La cronología de recipientes relativamente equivalentes, Gastria-Alaas sep. 6/8 y Amathus sep. 22, es el Protogeométrico o Geométrico Chipriota I, 1050-950 AC, mientras que el de Lapithos sep. 409 es asignable al Geométrico Chipriota II, 950-850 AC.

Una cuestión diferente es atribuir necesariamente estos recipientes a la metalurgia chipriota a falta de análisis de procedencia. El área egipcio-palestina presenta series mucho más amplias de recipientes metálicos, y no debemos olvidar que la asociación del vaso de Berzocana con dos torques de oro macizos, indica una cro-

T. P., 53, n. ${ }^{\circ} 2,1996$ 


\begin{tabular}{|l|l|l|}
\hline N. $^{\circ}$ de la Sepultura & Cronología & \multicolumn{1}{|c|}{ Bibliografía } \\
\hline Sepultura 914 & $1290-1214 \mathrm{AC}$ & Starkey y Harding, 1932: 22, lám. 48/37 \\
Sepultura 960 & $1290-1156 \mathrm{AC}$ & Starkey y Harding, 1932: 26, lám. 55/320 \\
Sepultura 822 & $c a .1200 \mathrm{AC}$ & Petrie, 1930: 9-10, lám. 28/822 \\
Sepultura 834 & $c a .1150 \mathrm{AC}$ & Petrie, 1930: 10, lám. 28/834 \\
Sepultura 532 & $1131-1112 \mathrm{AC}$ & Petrie, 1930: 7, lám. 21/93 \\
Sepultura 562 & Petrie, 1930: 7, lám. 21/97 \\
\hline
\end{tabular}

Tabla 6. Cuencos con pie en la necrópolis de Tell El-Far'ah-beth-Pelet (Israel). Cronologías de Petrie (1930) y Starkey y Harding (1932) revisadas.

nología antigua. En este sentido, los paralelos más claros están en Tell El-Far'ah-Beth-Pelet (Israel), aunque aparentemente carecen del ónfalo. Dos de ellos son recogidos por Radwan (1983: 98-99, taf. 50/270-271) ambos con diámetros de $15 \mathrm{cms}$., pero en las publicaciones originales encontramos varios más con una cronología relativamente amplia (Tabla 6 ).

Lo interesante es que se trata de una forma que se distribuye en un marco temporal relativamente restringido, entre la dinastía XIX y comienzos de la XXI, ca. 1307-1050 AC, lo cual se correlaciona mejor con una fecha del Bronce Final IC para los torques de oro, ya que parecen ser los precedentes y coetáneos de los cuencos chipriotas y de Berzocana.

En este sentido, algún autor como Pritchard (1968: 100, 109), apoyándose en lo espectaculares que resultan, en ocasiones, los hallazgos de vasos metálicos en Palestina y el valle del Jordán, y en las evidencias de trabajo metalúrgico en algún yacimiento, plantea que el área central del Jordán funcionó como un gran centro de metalurgia del bronce durante el Hierro I en Palestina, periodo equivalente al Chipriota Final IIIC. Busca apoyos a su hipótesis en Samuel (XIII) quien comenta que ca. 1025-1000 AC los filisteos tenían el monopolio de la fabricación de útiles de metal y que todos los israelitas dependían de éllos para proveerse de los mismos.

\section{LOS CONTACTOS LEVANTINO- CHIPRIOTAS CON EL MEDITERRÁNEO CENTRAL Y OCCIDENTAL}

Actualmente no podemos determinar quién aportó los artefactos importados presentes en ambas orillas del Mediterráneo, bien embarcaciones de áreas del Mediterráneo Occidental, bien alguna procedente del Mediterráneo Central, caso de Cerdeña o Sur de Italia, o quizás una embarcación chipriota en el viaje de retorno, sin entrar en hipótesis meramente especulativas hasta que algún pecio nos dé información indicativa en este sentido.

No obstante, lo primero que debemos tratar de definir es si se trata de productos llegados a lo largo de todo el Bronce Final o concentrados particularmente en unos periodos relativamente concretos, que nosotros situamos entre el Bronce Final IIC, y con más intensidad en el BF IIIA tipo Huelva, coetáneo con el Chipriota Final IIIB1- IIIB2 y el Protogeométrico o Geométrico Chipriota I, 1150-950 AC (Tabla 7).

Las fíbulas tipo Huelva parecen estar presentes durante todo este periodo en la Península Ibérica, si nos atenemos a las dataciones de San Román de la Hornija, ca. 1150 AC, Cerro de la Mora, ca. 1116 AC y Huelva, ca. 987-922 AC. La fíbula de codo tipo Huelva en Megiddo también tiende hacia fechas recientes, $c a$. 980-920 AC.

Para los asadores articulados suelen faltar buenas asociaciones, sin embargo, se dan datos interesantes en los ejemplares del Bronce Final Atlántico en la Península Ibérica. En Serra de Alvaiázere, los cinco ejemplares están acompañados por hachas unifaciales con una anilla. Otro tanto sucede en N.S. da Guía, Baiões, donde junto al asador articulado, contamos con moldes y hachas unifaciales de una anilla que podrían corresponderse con el Bronce Final IIC-IIIA, 1150-950 AC, con una posible reutilización o continuidad de las hachas de talón con dos anillas. El ejemplar chipriota de Amathus del Protogeométrico o Geométrico Chipriota I, 


\begin{tabular}{|c|c|c|c|}
\hline Cronología AC & Fíbulas tipo Huelva & Asadores Articulados & Vasos Metálicos tipo Berzocana \\
\hline 1300 & & & Beth Pelet, iBerzocana? \\
1250 & & & Beth Pelet \\
1200 & & & Beth Pelet \\
1150 & La Requejada & Beth Pelet \\
1100 & Cerro de la Mora & Alvaiázere, Baiões & Beth Pelet \\
1050 & Huelva, Amathus & Isleham & Beth Pelet, $i$ Berzocana? \\
1000 & Amathus & Aalas, Amathus \\
950 & Huelva, Megiddo & & Lapithos \\
900 & & & Lapithos \\
850 & Samaria & & Lapithos \\
800 & & & \\
\hline
\end{tabular}

Tabla 7. Secuencia de los productos ibéricos del Bronce Final Atlántico (fíbulas, asadores) y levantino-chipriota (vasos metáli$\cos$ ) objeto de tráfico comercial.

1050-950 AC, concuerda con las cronologías de Huelva.

Finalmente, en el depósito de Berzocana, los torques tienden a dar una cronología antigua pero, si nos atenemos a los paralelos chipriotas del cuenco metálico, particulamente los de Amathus sep. 22 y Lapithos sep. 409, ambos del Protogemétrico o Geométrico Chipriota I, 1050-950 AC, resultan coetáneos con el depósito de Huelva.

En suma, será durante el Bronce Final IIIA tipo Huelva y el Protogeométrico chipriota, $c a$. 1050-950 AC, cuando creemos que este tipo de relaciones se intensifican en ambas direcciones, y no es preciso remitirse exclusivamente al asador articulado de Amathus, como la evidencia más antigua de un renovado interés de comunidades del Mediterráneo Oriental por la Península Ibérica, tras un supuesto paréntesis comercial de un siglo en el Mediterráneo Central y Oriental (Burgess, 1991: 34, 36). Cabe plantearse, entonces, si en tales fechas se dieron unas condiciones especialmente favorables para este tipo de intercambios (Tabla 8).

El comercio chipriota tras alcanzar su cénit en el Chipriota Final IIA, durante el Chipriota Final IIB, $c a$. 1375-1300 AC, refleja un notable retroceso a juzgar por el número de cerámicas chipriotas en Palestina, su mercado más importante (Gittlen, 1981: 51; Åström, 1993: 311).

Al finalizar el Chipriota Final IIC, $c a$. 13001200/1190 AC, y Chipriota Final IIIA, ca. 1190$1175 \mathrm{AC}$, se advierte una brusca ruptura en los patrones de asentamiento chipriotas. Regiones naturales que han sido prospectadas sistemáti- camente muestran la ausencia de hábitats tras dicho periodo, caso de los valles de Vasilikos y Maroni (Todd y South, 1992: 203) o el de Alykos (Webb y Frankel, 1994: 20) en el sur de la isla. Poblados fortificados característicos de este último periodo como Maa-Palaeokastro, PylaKokkinokremos, Lara o Sinda (Karageorghis, 1982: 713, 723) son también abandonados.

Algunos autores lo interpretan como fruto del final de la demanda de cobre chipriota por el colapso producido en el Mediterráneo Oriental a raíz de la presencia de los Pueblos del Mar (Webb y Frankel, 1994: 21). La tesis tradicional, sin embargo, ha defendido que tras la destrucción de algunas poblaciones por los Pueblos del Mar, se produjo una arribada de pobladores micénicos a la isla de Chipre, apoyándose particularmente en la historia de Agapenor, lider de los Arcadios, recogida por Pausanias (VIII, 5, 2) (Gjerstad, 1944: 107-112, 123). Esta hipótesis sólo ha sido seriamente rechazada por Cook (1988: 14) quien, frente a la supuesta implantación de micénicos empujados por los dorios, reconoce mayores evidencias en el registro material que conectan con el Próximo Oriente. Lo paradójico es que el fósil director que se emplea para detectar a estos supuestos egeos micénicos en Chipre, la ceramica del Heládico Final IIIC: $1 \mathrm{~b}$, es el misma que se utiliza en el Levante para documentar la arribada de los filisteos, tal como apunta correctamente Mazar (1985: 105). Este ejemplo demuestra las potenciales incongruencias de dos líneas de investigación en regiones vecinas las cuales, a fin de buscar una ratificación arqueológica de dos tradiciones literarias

T. P., 53, n. ${ }^{\circ} 2,1996$ 


\begin{tabular}{|c|c|c|c|c|c|}
\hline Cronología & Estratigrafía & Comercio & Enterramientos & Hábitat & Destrucciones \\
\hline CF IIA & Enkomi IIa & $\begin{array}{l}\text { Incremento en } \\
\text { Siria-Palestina }\end{array}$ & $\begin{array}{l}\text { Inhumación } \\
\text { colectiva en } \\
\text { sepulturas } \\
\text { artificiales de } \\
\text { corredor corto } \\
\text { excavadas en el } \\
\text { suelo }\end{array}$ & $\begin{array}{c}\text { Fortificaciones } \\
\text { desde el CF I }\end{array}$ & \\
\hline CF IIB & Enkomi IIa & $\begin{array}{l}\text { Declive en Siria- } \\
\text { Palestina, } \\
\text { incremento en } \\
\text { Creta }\end{array}$ & $\begin{array}{l}\text { Sepulturas } \\
\text { artificiales en hoyo } \\
\text { y de mampostería } \\
\text { excavadas en el } \\
\text { suelo }\end{array}$ & Fortificaciones & \\
\hline CF IIC & $\begin{array}{l}\text { Sinda I } \\
\text { Enkomi IIc }\end{array}$ & $\begin{array}{l}\text { Declive en Siria- } \\
\text { Palestina y Creta, } \\
\text { incremento en } \\
\text { Grecia }\end{array}$ & $\begin{array}{l}\text { Sepulturas } \\
\text { artificiales en hoyo } \\
\text { y en fosa (novedad) }\end{array}$ & $\begin{array}{l}\text { Abandonos en } \\
\text { Apliki, Ayia Irini, } \\
\text { Myrtou y Pyla }\end{array}$ & $\begin{array}{l}\text { Enkomi, Kition, } \\
\text { Maa, Sinda }\end{array}$ \\
\hline CF IIIA1 & $\begin{array}{l}\text { Sinda II } \\
\text { Kition piso III-IIIa } \\
\text { Enkomi IIIa }\end{array}$ & $\begin{array}{l}\text { Declive en Grecia, } \\
\text { ¿incremento en } \\
\text { Sicilia y Cerdeña? }\end{array}$ & Continuidad & Reconstrucción & Enkomi, Sinda \\
\hline CF IIIA2 & $\begin{array}{l}\text { Sinda III } \\
\text { Kition piso III-IIIa } \\
\text { Enkomi IIIb }\end{array}$ & Declive & Continuidad & $\begin{array}{c}\text { Abandonos de } \\
\text { Apliki, Athienou, } \\
\text { Kourion, Hala } \\
\text { Sultan Tekke, Maa } \\
\text { y Sinda }\end{array}$ & Enkomi \\
\hline CF IIIB1 & $\begin{array}{l}\text { Kition piso II } \\
\text { Enkomi IIIc }\end{array}$ & Declive & $\begin{array}{l}\text { Sepultura artificial } \\
\text { rectangular con } \\
\text { corredor largo; } \\
\text { escasas cremaciones }\end{array}$ & Escaso poblamiento & Enkomi, Kition \\
\hline CF IIIB2 & Kition piso II & Declive & Continuidad & Escaso poblamiento & Enkomi, Kition \\
\hline $\begin{array}{l}\text { CF IIIC- } \\
\text { Protogeométrico GC I }\end{array}$ & Kition piso I & $\begin{array}{l}\text { Incremento en } \\
\text { Siria-Palestina }\end{array}$ & $\begin{array}{l}\text { Continuidad, } \\
\text { predominio } \\
\text { inhumación }\end{array}$ & Reconstrucción & \\
\hline
\end{tabular}

Tabla 8. Síntesis evolutiva de la secuencia chipriota entre el $\mathrm{CF}=$ Chipriota Final IIA y el Protogeométrico o Geométrico Chipriota I.

sobre hipotéticas colonizaciones, prefieren ignorarse mutuamente en este punto crucial.

La cuestión es que durante el Chipriota Final IIIB (Iacovou, 1989: 54), ca. 1150-1050 AC, hay un completo cambio de los patrones de asentamiento, continuando habitados sólo dos grandes hábitats, Kition en el Sureste y Palaepaphos en el Sur, mientras surgen nuevos núcleos de habitación. Del mismo modo, las necrópolis que habían sido reutilizadas entre el Chipriota Final I-IIIA son abandonadas utilizándose un nuevo tipo de sepultura, la tumba artificial con corredor.

Finalmente en el Protogeométrico o Geométrico Chipriota I, ca. 1050-950 AC, la evidencia indica que, frente a un mínimo número de importaciones egeas en Chipre con sólo tres vasos cerámicos del Heládico Final IIIC - Kaloriziki sep. 26 (Benson, 1973: 118), Kouklia y Kition (Daniel, 1937: 62, fig. 5-6) - hay una mayoritaria presencia de cerámica Sirio-Palestina. Entre ella destacan las jarras "cananitas", indicativas de la continuidad de los lazos con el Levante, ya que en el puerto de Hala Sultan Tekke, durante el Chipriota Final IIIA1 (Åström, 1991: 150) antes de su destrucción, eran la forma cerámica más abundante. Otras jarras de Kition procedían de Ashdod en Palestina (Gunneweg et alii, 1987: 169-171), una de las áreas donde posteriormente se asentarán primero los filisteos. 
Asumiendo que Chipre se mueve en la órbita económica de las ciudades costeras del Levante en el periodo que nos interesa del Bronce Final IIIA Atlántico de la Península Ibérica, la cuestión es cuál sería la región litoral dominante del Mediterráneo Oriental.

La dinastía XXI egipcia con Smendes (10771044 AC) ya no era lo que fue, tal como refleja el viaje de su enviado a la costa levantina, WenAmon (Albright, 1951) hacia 1050 AC. Alguno de los antiguos grandes núcleos urbanos costeros septentrionales como Biblos mostraba signos de recesión desde finales del Imperio Nuevo (Albright, 1950: 165). Mientras otros, caso de Ugarit, habían sido destruidos aparentemente por los Pueblos del Mar. Ello sólo nos deja dos alternativas: el núcleo fenicio, Sidón y Tiro, alrededor del actual Líbano o los filisteos en Palestina.

Si combinamos las referencias históricas con los datos arqueológicos claves que disponemos, se advierte que hacia $1050 \mathrm{AC}$ los filisteos derrotan militarmente a los israelitas en Ebenezer (Izbet Sartah) y se extienden hacia la Judea central. Por otra parte, el puerto de Dor, habitado por otro de los denominados Pueblos del Mar, los Sikuli-Sikilo-Sekel, que entonces con Sidón era uno de los dos puertos más importantes del Levante, presenta a partir del $1050 \mathrm{AC}$, estrato IX, un notable número de cerámicas Pintadas Blancas I del Chipriota Final IIIC (Stern, 1993: 331-332). Éstas ponen en evidencia que la ruptura de los lazos comerciales con Chipre se circunscribe al 1150-1050 AC, el Chipriota Final IIIB, y nos indican la primacía de los filisteos, claramente al menos hasta $c a$. $1000 \mathrm{AC}$, los cuales, aparentemente, además están cooperando con los sidonios de acuerdo con varias alusiones presentes en el Antiguo Testamento.

En los cincuenta años posteriores, sin embargo, se van a producir una serie de rápidos cambios que afectarán al mapa político de la región. Inicialmente, la caída de dos colonias asirias cerca de Carchemish durante el reino de Ashur-rabi II (1012-972 AC) en manos de un rey arameo cortará los lazos entre Asiria y el Mediterráneo (Ikeda, 1982: 233). Este hecho, que sucedió bajo el mandato del rey David en Israel (1000-961 AC) (Albright, 1950:174), va a coincidir con el inicio de una nueva dinastía en Tiro, cuyo primer monarca, Abibaal (ca. 1000970 AC) (Katzenstein, 1973: 74, 349), va a romper los lazos de su ciudad con los filisteos, y probablemente con los sidonios, a raíz de la victoria de David sobre los filisteos hacia $c a$. 975 AC, sellando entonces Abibaal una presumible alianza con David para romper la hegemonía marítima y terrestre filistea (com. pers. de Albright a Katzenstein, 1973: 75).

Todo ello será posible aprovechando los problemas de Asiria en su enfrentamiento con los arameos (vide supra) y los problemas internos en Egipto durante el III Periodo Intermedio, con una serie de faraones débiles durante la XXI dinastía, como Amenemope (993-984 AC) y Osorkón I (984-978 AC), que se verán afectados por la fractura del país entre el reino de Tanis en el norte y una teocracia en Tebas que controlará las regiones meridionales.

A partir de entonces, con la alianza de Hiram I y Salomón, se abre una nueva etapa que supera los límites de este trabajo. Sin embargo, es importante señalar que ya en tiempos de Abibaal, padre de Hiram I, aparentemente la ciudad chipriota de Kition será conquistada, e Hiram posteriormente dirigirá una expedición contra la misma por negarse a pagar tributo a Tiro (Katzenstein, 1973: 84).

De acuerdo con los puntos ya mencionados, para el periodo entre $c a$. 1050-950 AC se aprecia una clara hegemonía de los filisteos entre ca. 1050-1000 AC, que probablemente les otorgó ventaja en el comercio hacia el Mediterráneo Occidental aprovechando rutas entonces menos transitadas tras los problemas comerciales en el Mediterráneo Oriental durante el periodo de las invasiones de los Pueblos del Mar, ca. 1200-1050 AC.

En la segunda parte de este periodo, $c a$. 1000-950 AC, la situación adquirirá mayor complejidad con una presumible coexistencia y rivalidad entre los filisteos y los tirios por el control de las rutas comerciales a larga distancia, rivalidad que probablemente afectó también al comercio y control de ciudades chipriotas.

Cabe entonces plantear la hipótesis de que en este último momento se va a producir en Chipre la coexistencia de una influencia filistea

T. P., 53, n. ${ }^{\circ} 2,1996$ 
en la actual región de Limasol, bahías de Episkopi (Kourion) y Akrotiri (Amathus), y una influencia o incluso dominio tirio en la actual región y bahía de Larnaca (Kition). El hecho de que en la inscripción de Esarhaddon, 673-672 $\mathrm{AC}$ se mencionen como reinos independientes, Kition, Amathus y Kourion, favorece la posibilidad de una potencial división política entre dichas regiones, en periodos previos al siglo VII $\mathrm{AC}$, con intereses distintos y posible rivalidad comercial.

En este marco de relaciones habría que interpretar la ahora más lógica presencia de alguna fíbula tipo Huelva en Megiddo VA, cuyo puerto más inmediato es Dor, o en el mismo sentido, que el asador articulado de Amathus y las fíbulas de codo tipo Huelva de Kourion y Amathus aparezcan en las regiones meridionales de Limasol y Larnaca.

Datos que apoyarían la tesis de Albright (com. pers. a Katzenstein, 1973: 75) sobre las alianzas tirias con los israelitas -Abibaal y David, Hiram y David, Hiram y Salomón- para desbancar a los filisteos de las rutas con el Mediterráneo Central y Occidental podrían encontrarse en cómo los tirios dejan también a Israel beneficiarse comerciando con Ophir en el Mar Rojo, aprovechando la decadencia egipcia en el control de esas rutas, mientras en otras ocasiones imposibilitan a los israelitas acceder a cualquier tipo de control comercial en el Mediterráneo y no hay evidencias de colaboración mutua.

En este sentido es interesante la observación de Ikeda (1982: 234) sobre cómo los tirios rechazan la presencia de agentes israelitas en el comercio de madera, desde su tala en los montes del Líbano hasta su transporte a la costa israelita, cuando se produce una petición en este sentido de Salomón a Hiram.

No obstante, frente a este énfasis en la capacidad de maniobra tiria, que en ningún caso parece que se enfrenta militarmente a sus antiguos aliados, los filisteos, creemos que la anulación práctica de la antigua preponderancia filistea va a resultar de un pacto entre Egipto e Israel.

A finales de la Dinastía XXI, con el penúltimo faraón, la situación comienza a cambiar y se reanudará la política intervencionista en la región de Gaza. El faraón Siamón (978-958 AC) enviará una expedición militar que arrasará varias ciudades filisteas destruyendo Tel Mor (nivel III), quizás Beth-Shemesh (nivel IIb) y Gezer, y situará a Filistea bajo la órbita política egipcia (Malamat, 1963: 12-13, 17). Esta operación se cerrará con un pacto entre el faraón y Salomón, sellado con el matrimonio del rey israelita con la hija de Siamón, a la cual el faraón concederá en dote la ciudad de Gezer y los territorios inmediatos.

Así pues, surge un panorama más complejo que atribuir simplemente (Burgess, 1991: 40) a fenicios operando vía Chipre-Sicilia-Cerdeña el transporte del asador de Amathus a oriente y la fíbula de codo tipo Huelva a occidente, modelo que además creemos de procedencia occidental.

En conclusión, el punto clave que conviene resaltar es que entre $c a$. 1050-950 AC hubo un proceso de intensificación de relaciones entre el eje Filisteo-Chipriota con la Península Ibérica, quizás también buscando acceder a los recursos mineros ibéricos, en el cual los fenicios de Tiro y los chipriotas de Kition tratarán de participar a partir del ca. 975 AC. Esta segunda opción se consolidará con el cambio de relaciones de poder en el Levante y la ya definitiva decadencia filistea, a partir del 960-950 AC en adelante, tras la campaña del faraón Siamón.

\section{VISIONES DESDE LA PERIFERIA}

Si nos preguntamos qué impresión produce este tipo de intercambios desde un punto de vista estricto de las relaciones Centro-Periferia (Sherratt y Sherratt, 1991; Frank, 1993; Mederos, 1995), y hasta qué punto incidieron económicamente en la Península Ibérica es obvio que, cuantitativamente, no puede hablarse de un volúmen de intercambios importante entre ambos extremos del Mediterráneo. Cualquier intento de argumentar una relación de dependencia entre un Centro situado en las regiones del Levante y Próximo Oriente, caso de Asiria, y una aparente región periférica como sería la Península Ibérica, exige un enfoque minimalista. La relación además, cuando se produce, es a través de estados litorales o insulares menos importantes. 
Si observamos los intercambios desde un punto de vista cualitativo, quizás la visión no resulte tan negativa. En principio, frente a la hipótesis de trabajo precedente sobre "contacto precolonial", que suponía la presencia de intercambios de productos de lujo de manufactura oriental a cambio de materias primas, nos encontramos ante un panorama más complejo. También productos manufacturados atlánticos, como los asadores articulados o las fíbulas de codo tipo Huelva, parecen alcanzar el Mediterráneo Oriental, y más concretamente, Chipre y la costa del Levante.

Se podrá rebatir nuestra argumentación cronológica y técnica de las fíbulas, pero ello resulta más difícil para el caso de los asadores articulados. La evidencia puede considerarse parca si nos atenemos exclusivamente a los artefactos y no a representaciones iconográficas en las estelas decoradas del Suroeste, tradicionalmente consideradas de origen oriental (Almagro Gorbea, 1989: 280-282). Frente a unas pocas fíbulas y un único asador sólo podemos esgrimir el vaso metálico de Berzocana como una contrapartida con ciertas garantías de posible fabricación en el Mediterráneo Oriental.

En segundo lugar, es obvio que nos encontramos ante productos destinados a las élites. Pero no sólo son regalos o bienes de intercambio de los mercaderes orientales para las clases dirigentes indígenas de la Península Ibérica, sino que también los productos manufacturados occidentales terminan en manos de personajes chipriotas importantes.

El vaso metálico de Berzocana, acompañado por dos torques macizos de oro, es un claro ejemplo en la Península Ibérica. Otro tanto cabe decir de la sepultura 523 de Amathus en Chipre, de donde procede el asador articulado y una fíbula de codo que iría sujetando una túnica. Esta tumba está considerada una de las más ricas de la necrópolis, destacando la presencia de adornos discoidales de oro, un sello de faienza, un escarabeo de oro, un puñal de hierro con mango de marfil, etc. (Karageorghis, 1987: 719-723). En todos estos objetos, incluidos el asador articulado y la fíbula, está inherente el valor que se otorga a un producto de lujo bien elaborado, pero a él se agrega la dificultad de acceso a los mismos, interviendo aquí el valor suplementario que adquieren durante su transporte desde ambas márgenes del Mediterráneo, que incrementa su valor final y los hace más deseables.

Un tercer punto que cabe inferir de este razonamiento es que, si se trata de objetos de lujo intercambiados, al menos en parte, como regalos para sellar algún tipo de acuerdo comercial que dé cierta lógica a estos largos y arriesgados desplazamientos a través del Mediterráneo, presumiblemente también debieron haber intervenido en la negociación otros productos quizás no tan elaborados, pero igualmente deseables, de momento invisibles en el registro arqueológico, como materias primas, telas, productos aromáticos, etc.

Finalmente una última anotación que tiene trascendencia para todos los modelos de comercio dentro de una óptica de Centro-Periferia, y que da soporte a la noción y coexistencia de varios Sistemas Mundiales Antiguos. No existe un único Centro que generalmente controle o mediatice la toma de decisiones de todos los estados o unidades sociopolíticas que giran alrededor de él. Esto sólo sucedía en el periodo objeto de análisis en el caso de un verdadero centro como Asiria. Los estados son independientes políticamente, inclusive aunque cuentan con relaciones de dependencia económica respecto al Centro, y toman decisiones propias actuando autónomamente, como demuestra la búsqueda de nuevos mercados en el Mediterráneo Occidental por parte de algunas ciudades del Levante y Chipre, antes de que se acentuase la presión asiria que culminó en la conquista de ambos territorios.

\section{AGRADECIMIENTOS}

Deseamos agradecer los comentarios de R.J. Harrison al texto. Mrs. S. Grice realizó el sombreado de la figura 4.

\section{BIBLIOGRAFÍA}

Albright, W.F. (1940): "Review of Megiddo I. Season of 1925-34, Strata I-V by R.S. Lamon and G.M. Shipton". American Journal of Archaeology, 44: 546-550. 
- (1950): "Some Oriental Glosses on the Homeric Problem". American Journal of Archaeology, 54: 162-176.

- (1951): "The Eastern Mediterranean about 1060 BC". En G.E. Mylonas (ed.): "Studies Presented to David M. Robinson". Washington University. Saint Louis. Missoury: 223-231.

Almagro Basch, M. (1940): "El Hallazgo de la Ría de Huelva y el Final de la Edad del Bronce en el Occidente de Europa". Ampurias, 2: 85-143.

- (1957-58): "A propósito de la fecha de las fíbulas de Huelva”. Ampurias, 19-20: 198-207.

- (1958): "Depósito de la Ría de Huelva”. Inventaria Archaeologica. España. Fascículo 1-4. E-1. Instituto Español de Prehistoria. Madrid.

- (1966): Las estelas decoradas del Suroeste peninsular. Bibliotheca Praehistorica Hispana,VIII. Madrid.

- (1967): Inventaria Archaeologica. España. Fascículo 7. E. 11-E. 19. Madrid.

- (1969): "De orfebrería céltica. El depósito de Berzocana y un brazalete del Museo Arqueológico Nacional". Trabajos de Prehistoria, 26: 275-287.

- (1974): "Nuevas estelas decoradas de la Península Ibérica". En E. Ripoll y M. Llongueras (eds.): "Miscelánea Arqueológica. XXV aniversario de los cursos internacionales de prehistoria y arqueología en Ampurias (1947-1971)". Barcelona: 5-39.

Almagro Gorbea, M. (1974): "Los asadores de bronce del Suroeste peninsular". Revista de Archivos, Bibliotecas y Museos, 77: 351-395.

- (1977): El Bronce Final y el Período Orientalizante en Extremadura. Bibliotheca Praehistorica Hispana, XIV. Madrid.

- (1986): "El Bronce Final y el inicio de la Edad del Hierro en la Península Ibérica". En Historia de España I. Prehistoria. Editorial Gredos. Madrid: 341-532.

- (1989): "Arqueología e Historia Antigua: El proceso protoorientalizante y el inicio de los contactos de Tartessos con el Levante mediterráneo". En J.M. Blázquez y J. Martínez Pinna (eds.): "Estudios sobre Antigüedad en Homenaje al Profesor Santiago Montero Díaz”. Anejos de Gerión, II. Universidad Complutense. Madrid: 277-288.

Alvar, J. (1988): "La Precolonización y el tráfico marítimo fenicio por el estrecho". I Congreso Internacional El Estrecho de Gibraltar (Ceuta, 1987). I. Universidad Nacional de Educación a Distancia. Madrid: 429-443.

ÅstrÖM, P. (1991): "Canaanite Jars from Hala Sultan Tekke". En N.H. Gale (ed.): "Bronze Age Trade in the Mediterranean" (Oxford, 1989). Studies in Mediterranean Archaeology, 90: 149-151. Jonsered.

- (1993): "Late Cypriot Bronze Age Pottery in Palestina". En "Biblical Archaeology Today 1990". $2^{\text {nd }}$ International Congress on Biblical Archaeology (Jerusalem, 1990). Israel Exploration Society. Jerusalem: 307-313.

Benson, J.L. (1973): The Necropolis of Kaloriziki. Studies in Mediterranean Archaeology, 36. Göteborg.

Bigoteau, M. (1974-75): "Collection d'objets de bronze 'Ch. Mercier' déposée au Museum d'Histoire Naturelle de Nantes". Maîtrise et Etudes Pré et Protohistoriques Pays de la Loire, 4: 127-147.
Birmingham, J. (1963): "The Development of the Fibula in Cyprus and the Levant". Palestine Exploration Quaterly, 95: 80-112.

BLÁzQUEZ, J.M. ${ }^{a}$ (1968): Tartessos y los orígenes de la colonización fenicia en Occidente. Acta Salmanticensia. Filosofía y Letras, 85. 2. ${ }^{\text {a }}$ ed. revisada, 1975. Salamanca.

- (1985-86): "Los escudos con escotadura en V y la presencia fenicia en la costa atlántica y en el interior de la Península Ibérica". Veleia, 2-3: 469-497.

BlinkenberG, C. (1926): Fibules Grecques et Orientales. Det Kgl. Danske Videnskabernes Selskab, Historisk-filologiske Meddelelser, XIII/1. Bianco Lunos. Kobenhavn.

BRIARD, J. (1965): Les dépôts bretons et l'Age du Bronze atlantique. Travaux du Laboratoire d'Anthropologie Préhistorique. Faculté des Sciences. Rennes.

Briard, J.: Cordier, G. y Gaucher, G. (1969): “Un dépôt de la fin du Bronze Moyen à Malassis, commune de Chéry (Cher)". Gallia-Préhistoire, 13/1: 37-73.

BuCHHOLZ, H.G. (1986): "Ein kyprischer Fibeltypus und seine auswärtige Verbreitung". En V. Karageorghis (ed.): "Cyprus between the Orient and the Occident" (Nicosia, 1985). Department of Antiquities. Nicosia: 233-244.

Burgess, C. (1991): "The East and the West: Mediterranean influence in the Atlantic World in the Later Bronze Age, c. 1500-700 B.C.". En C. Chevillot y A. Coffyn (eds.): "L'Age du Bronze Atlantique”. Association des Musées du Sarladais. Beynac-et-Cazenac: 25-45.

Callejo, C. y Blanco Freijeiro, A. (1960): "Los torques de oro de Berzocana (Cáceres)". Zephyrus, 11: 250-255.

Cardozo, M. (1946): "Carrito votivo de bronce, del Museo de Guimaraes (Portugal)". Archivo Español de Arqueología, 19: 1-28

CARrasco, J.; PAChÓn, J.A. y PAStor, M. (1985): "Nuevos hallazgos en el conjunto arqueológico del Cerro de la Mora. La espada de Lengua de Carpa y la fíbula de codo del Cerro de la Miel (Moraleda de Zafayona, Granada)". Cuadernos de Prehistoria de la Universidad de Granada, 10: 265-333.

Cesnola, L.P. DI (1903): A descriptive Atlas of the Cesnola collection of Cypriot antiquities in the Metropolitan Museum of Art, New York. Metropolitan Museum of Art. Boston-New York.

- (1991): "Le Périgord, un terroir a la croisée des complexes atlantique et nord-alpin". En C. Chevillot y A. Coffyn (eds.): "L'Age du Bronze Atlantique". Association des Musées du Sarladais. Beynac-et-Cazenac: 145-164.

Coffyn, A. (1985): Le Bronze Final Atlantique dans la Péninsule Ibérique. Picard. Paris.

Coffy, A. y Sion, H. (1993): "Les relations atlanto-méditerranées. Eléments pour une révision chronologique du Bronze final atlantique". Mediterrâneo, 2: 285-310.

Coles, J.M. (1962): "European Bronze Shield Series". Proceedings of the Prehistoric Society, 28: 156-190.

СоOK, V. (1988): "Cyprus and the Outside World during the Transition from the Bronze Age to the Iron Age". Opuscula Atheniensia, 17: 13-32. 
Crowfoot, J.W.; Crowfoot, G.M. y Kenyon, K.M. (1957): Samaria-Sebaste. III. The objects from Samaria. Reports of the Work of the Joint Expedition in 19311933 and of the British Expedition in 1935. Palestine Exploration Fund. London.

Chevillot, C. (1989): Sites et cultures de l'Âge du Bronze en Périgord (Du Groupe d'Artenac au Groupe de Vénat). Archéologies, 3. Editions Vesuna. Périgueux.

DANIEL, J.F. (1937): "Two Late Cypriote III tombs from Kourion". American Journal of Archaeology, 41: 56-85.

Delibes de Castro, G. (1978): "Una inhumación triple de la facies Cogotas I en San Román de Hornija (Valladolid)". Trabajos de Prehistoria, 35: 225-250.

Frank, A.G. (1993): "Bronze Age World System Cycles". Current Anthropology, 34/4: 383-429.

GJeRsTAD, E. (1944): "The Colonization of Cyprus in Greek Legend". Opuscula Archaeologica, 3: 107-123.

- (1948): The Swedish Cyprus Expedition IV/2. The Swedish Cyprus Expedition. Stockholm.

GonzÁlez Salas, S. (1945): "El Castro de Yecla, Santo Domingo de Silos (Burgos)". Informes y Memorias, 7. Madrid.

Guido, M. (1963): Sardinia. Thames and Hudson. London.

Gunneweg, J.; Perlman, I. y Asaro, F. (1987): “A Canaanite Jar from Enkomi”. Israel Exploration Journal, 37: 168-172.

HARRISON, R.J. (1974-75): "Nota acerca de algunas espadas del Bronce Final en la Península Ibérica". Ampurias, 36-37: 225-233.

- (1988): Spain at the Dawn of History. Thames and Hudson. London.

HAWKES, C.F.C. (1952): "Las relaciones en el bronce final, entre la Península Ibérica y las Islas Británicas con respecto a Francia y la Europa Central y Mediterránea". Ampurias, 14: 81-119.

- (1971): "The Sintra Gold Collar". The British Museum Quaterly, 35/1-4: 38-50.

Hencken, H. (1956): "The Fibulae of Huelva". Proceedings of the Prehistoric Society, 22: 213-215.

IAcovou, M. (1989): "Society and settlements in Late Cypriot III". En E. Peltenburg (ed.): "Early Society in Cyprus". Edinburgh University Press. Edinburgh: 5259.

IKEDA, Y. (1982): "Solomon's Trade in Horses and Chariots in Its International Setting". En T. Ishida (ed.): "Studies in the Period of David and Solomon and other Essays". Yamakawa-Shuppansha: 215-238.

KalB, PH. (1980): "Zur atlantischen Bronzezeit in Portugal". Germania, 58: 25-59.

KARAgEORGHIs, V. (1982): "Deux avant-postes militaires de la fin du XIII ${ }^{\mathrm{e}}$ siecle av. J.C. à Chypre". Comptes Rendus de l'Academie des Inscriptions et Belles-Lettres, 1982: 704-724.

- (1987): "Chronique des fouilles et découvertes archéologiques à Chypre en 1986". Bulletin de Correspondance Hellenique, 111: 663-733.

Karageorghis, V. y Lo Schiavo, F. (1989): “A West Mediterranean Obelos from Amathus". Rivista di Studi Fenici, 17/1: 15-29.
Katzenstein, H.J. (1973): The History of Tyre. From the Beginning of the Second Millenium B.C.E. until the Fall of the Neo-Babylonian Empire in 538 B.C.E.. The Schocken Institute for Jewish Research. Jerusalem.

Kempinski, A. (1989): Megiddo. A City-State and Royal Centre in North Israel. Materialien zur Allgemeinen und Vergleichenden Archäologie, 40. Verlag C.H. Beck. München.

LAmON, R.S. Y SHIPTON, G.M. (1939): Megiddo I: Seasons of 1925-34, Strata $I-V$. Oriental Institute Publications, 42. The University of Chicago Press. Chicago.

LA RosA, V. (1979): "Sopralluoghi e ricerche attorno a Milena, nella media valle del Platani". Cronache di Archeologia, 18: 1-27.

Lo Schiavo, F. (1978): "Bronzi dalla Grotta "Su Benticheddu", Oliena". En Sardegna Centro-Orientale dal Neolitico alla fine del Mondo Antico. Sassari: 89-91.

- (1991): "La Sardaigne et ses Relations avec le Bronze Final Atlantique". En C. Chevillot y A. Coffyn (eds.): "L'Age du Bronze Atlantique". Association des Musées du Sarladais. Beynac-et-Cazenac: 213-226.

- (1993): "Un 'Altra Fibula 'Cipriota' dalla Sardegna". En R.H. Tykot y T.K. Andrews (eds.): "A Footprint in the Sea. Studies in Sardinian Archaeology Presented to Miriam S. Balmuth". Sheffield Academic Press. Sheffield: 296-303.

Lo Schiavo, F.; MacNamara, E. y VagnetTi, L. (1985): "Late Cypriot imports to Italy and their influence on local bronzework". Papers of the British School at Rome, 53: 1-71.

Loud, G. (1948): Megiddo II. Seasons 1935-9. Oriental Institute Publications, 62. University of Chicago Press. Chicago.

Malamat, A. (1963): "Aspects of the Foreign Policies of David and Solomon". Journal of Near Eastern Studies, 22/1: 1-17.

MALUQUER DE MOTES, J. (1958): Excavaciones arqueológicas en el Cerro del Berrueco (Salamanca). Acta Salmanticensia, XIV. Salamanca.

MAтThÄus, H. (1985): Metallgefäbe und GefäBuntersätze der Bronzezem, der geometrischen und archaischen Periode auf Cypern mit einem Anhang der bronzezeitlichen Schwertfunde auf Cypern. Prähistorische Bronzefunde, II/8. C.H. Beck'sche Verlag. München.

MAZAR, A. (1985): "The Emergence of the Philistine Material Culture". Israel Exploration Journal, 35: 95-107.

Mederos Martín, A. (1995) “¿Retorno al pasado?. Comercio o difusión en los análisis de los Sistemas Mundiales Antiguos". Trabajos de Prehistoria, 52/2: 131-141.

Mendoza, A.; Molina GonzÁlez, F.; Arteaga, O.; Aguayo, P.; SÁez, L.; Roca, M.; Contreras, F. y CARrión, F. (1981): "Cerro de los Infantes (Pinos Puente, Provinz Granada). Ein Beitrag zur Bronzeund Eisenzeit in Oberandalusien". Madrider Mitteilungen, 22: 171-210.

MERRILLEES, R.S. (1992): "The Absolute Chronology of the Bronze Age in Cyprus: A Revision". Bulletin of the American School of Oriental Research, 288: 47-52.

MoHen, J.P. (1977): "Les broches à rôtir de l'Age du Bronze". Antiquités Nationales, 9: 34-39.

T. P., 53, n. ${ }^{\circ} 2,1996$ 
Molina GonzÁlez, F. (1978): “Definición y sistematización del Bronce Tardío y Final en el Sudeste de la Península Ibérica". Cuadernos de Prehistoria de la Universidad de Granada, 3: 159-232.

MorÁn, C. (1921): El Cerro del Berrueco en los límites de Ávila y Salamanca. Salamanca.

- (1923-24): Excavaciones en el Cerro del Berrueco (Medinilla, Avila, El Tejado y Puente Congosto, Salamanca). Memorias de la Junta Superior de Excavaciones y Antigüedades, 65. Madrid.

Myres, J.L. (1914): Handbook of the Cesnola Collection of Antiquities from Cyprus. Metropolitan Museum of Art. New York.

NiEMEYER, H.G. (1984): "Die Phönizier und die Mittelmeerwelt im Zeitalter Homers". Jahrbuch des RömischGermanischen Zentralmuseums, 31: 3-94.

O' Connor, B. (1980): Cross-Channel Relations in the Later Bronze Age. British Archaeological Reports, International Series, 91. Oxford.

Orsi, P. (1895): "Thapsos". Reale Accademia dei Lincei. Monumenti Antichi, 6: 89-150.

- (1897): "Nuovi materiali siculi del territorio di Girgenti”. Bullettino di Paletnologia Italiana, 23: 8-15.

Perea Caveda, A. (1991): Orfebrería prerromana. Arqueología del Oro. Caja de Madrid-Comunidad de Madrid. Madrid.

Petrie, F. (1930): Beth-Pelet I (Tell Fara). British School of Archaeology in Egypt. London.

Pritchard, J.B. (1968): "New Evidence on the Role of the Sea Peoples in Canaan at the Beginning of the Iron Age". En W.A. Ward (ed.): "The Role of the Phoenicians in the Interaction of Mediterranean Civilizations" (Beirut, 1967). American University of Beirut. Beirut: 99-112.

Radwan, A. (1983): Die Kupfer-und BronzegefäBe Ägyptens (Von den Anfängen bis zum Beginn der Spätzeit). Prähistorische Bronzefunde, II/2. C.H. Beck'sche Verlag. München.

RowLANDS, M.J. (1971): "A group of incised decorated armrings and their significance for the Middle Bronze Age of southern Britain". British Museum Quaterly, 35/1-4: 183-199.

Ruiz-GÁlvez Priego, M.L. (1984): “La Península Ibérica y sus relaciones con el círculo cultural atlántico”. Universidad Complutense de Madrid. Madrid.

- (1986): "Navegación y comercio entre el Atlántico y el Mediterráneo a fines de la Edad del Bronce". Trabajos de Prehistoria, 43: 9-42.

- (1993): "El Occidente de la Península Ibérica, punto de encuentro entre el Mediterráneo y el Atlántico a fines de la Edad del Bronce". Complutum, 4: 41-68.

- (1995): Ritos de Paso y puntos de paso: La ría de Huelva en el mundo del Bronce Final Europeo. Complutum. Extra, 5. Universidad Complutense. Madrid.
SCHAuER, P. (1983): "Orient im spätbronze- und früheisenzeitlichen Occident Kulturbeziehugen zwischen der Iberischen Halbinsel und der vorderen Orient während des spätens zweiten und des ersten Drittels des I. Jahrtausends v. Ch.". Jahrbuch des Römish-Germanischen Zentralmuseums, 30: 175-194.

SCHÜlE, W. (1969): Die Meseta-Kulturen der Iberischen Halbinsel. Mediterrane und Eurasische Elemente in Früheisenzeitlichen Kulturen Südwesteuropas. Madrider Forschungen, 3. Walter de Gruyter. Berlin.

SherratT, A. Y Sherratt, S. (1991): "From luxuries to commodities: The Nature of Mediterranean Bronze Age Trading Systems". En N.H. Gale (ed.): "Bronze Age trade in the Mediterranean". Studies in Mediterranean Archaeology, 90: 351-386. Jonsered.

Silva, A.C.F. DA; SIlva, C.T. y Lopes, A.B. (1984): "Depósito de fundidor do final da Idade do Bronze do castro da Senhora da Guía (Baiões, S. Pedro do Sul, Viseu)". En "Lucerna. Homenagem a D. Domingos de Pinho Brandão”. Centro de Estudos Humanísticos. Porto: 73-95.

Starkey, J.L. Y HARding, L. (1932): Beth-Pelet II. BethPelet Cementery. British School of Archaeology in Egypt. London.

STERN, E. (1993): "The Renewal of Trade in the Eastern Mediterranean in Iron Age I". En "Biblical Archaeology Today 1990”. $2^{\text {nd }}$ International Congress on Biblical Archaeology (Jerusalem, 1990). Israel Exploration Society. Jerusalem: 325-334.

Stuiver, M. Y Reimer, P.J. (1993): "Extended C-14 data base and revised Calib $3.0 \mathrm{C}-14$ age calibration program". Radiocarbon, 35/1: 215-230.

TARAMELli, A. (1921): "Il ripostiglio di bronzi nuragici di Monte Sa Idda di Decimoputzu (Cagliari)". Reale Accademia dei Lincei. Monumenti Antichi, 27: 5-98.

TodD, I.A. y South, A. (1992): “The Late Bronze Age in the Vasilikos Valley: recent research". En G.C. Ioannides (ed.): "Studies in Honour of Vassos Karageorghis". Society of Cypriot Studies. Nicosia: 191-204.

TYкOT, R.H. (1994): "Radiocarbon dating and absolute chronology in Sardinia and Corsica". En R. Skeates y R. Whitehouse (eds.): "Radiocarbon Dating and Italian Prehistory". Archaeological Monographs of the British School at Rome, 8-Accordia Specialist Studies on Italy, 3. London: $115-145$.

VAGNETTI, L. (1968): "I bacili di bronzo di Caldare sono ciprioti?". Studi Micenei ed Egeo Anatolici, 7: 129-138.

VILAÇA, R. (1990): "Broche à rôtir articulée de Cachouça (Idanha-a-Nova, Castelo Branco, Portugal)". Bulletin de la Société Prehistorique Française, 87/6: 167-169.

WEBB, J.M. y FrANKEL, D. (1994): "Making an Impression: Storage and Surplus Finance in Late Bronze Age Cyprus". Journal of Mediterranean Archaeology, 7/1: 5-26.

Wightman, G.J. (1985): "Megiddo VIA-III: Associated Structures and Chronology". Levant, 17: 117-129. 